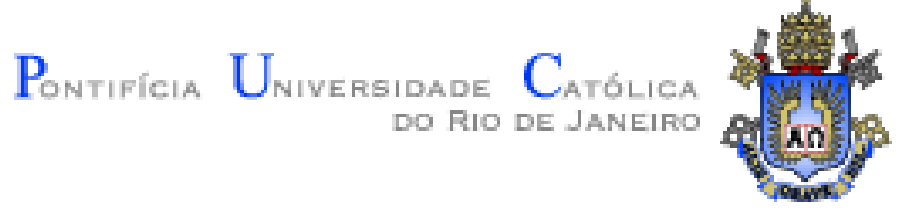

Felipe Ruiz Mazin

\title{
Dissecting Chimerica
}

A Structural Decomposition of Global Imbalances

Dissertação de Mestrado

Dissertation presented to the Programa de Pós-Graduação em Economia of the Departamento de Economia, PUC-Rio as partial fulfillment of the requirements for the degree of Mestre em Economia.

Advisor: Prof. Carlos Viana de Carvalho 


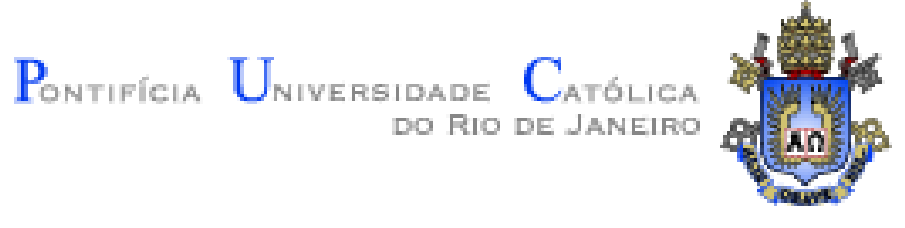

Felipe Ruiz Mazin

\title{
Dissecting Chimerica
}

A Structural Decomposition of Global Imbalances

Dissertation presented to the Programa de Pós-Graduação em Economia of the Departamento de Economia do Centro de Ciências Sociais da PUC- Rio as partial fulfillment of the requirements for the degree of Mestre em Economia.Approved by the following commission:

\author{
Prof. Carlos Viana de Carvalho \\ Advisor \\ Departamento de Economia - PUC-Rio
}

Prof. Eduardo Zilberman

Department of Economics - PUC-Rio

Prof. Pedro Cavalcanti Ferreira

Fundação Getulio Vargas

Prof. Monica Herz

Coordenadora Setorial do Centro de Ciências Sociais - PUC-Rio

Rio de Janeiro, April 21 ${ }^{\text {th }}, 2014$ 
All rights reserved.

Felipe Ruiz Mazin

B.A., Economics, Fundação Getulio Vargas, 2007-2011 (São Paulo, Brazil).

Mazin, Felipe Ruiz

Dissecting Chimerica: A Structural Decomposition of Global Imbalances / Felipe Ruiz Mazin; advisor: Carlos Viana de Carvalho. - Rio de Janeiro : PUC-Rio, Departamento de Economia, 2014.

v., 62 f: il. ; $29,7 \mathrm{~cm}$

1. Dissertação (Mestrado em Economia) - Pontifícia Universidade Católica do Rio de Janeiro, Departamento De Economia.

Inclui Bibliografia.

1. Economia - Dissertação. 2. Desequilíbrios Globais. 3. Crescimento de Produtividade. 4. Tendências Demográficas. 5. Previdência Social. 6. Custos de Portfólio. I. Carvalho, Carlos Viana de. II. Pontifícia Universidade Católica do Rio de Janeiro. Departamento de Economia. III. Título. 


\section{Acknowledgments}

First of all, I would like to thank my parents, without whom none of this would be possible. I am grateful for their unconditional love and emotional support in what was definitely the most challenging period in my life.

I am also grateful to my advisor, Professor Carlos Viana de Carvalho, whose helpful advice and guidance were absolutely necessary. I also thank the thesis committee, composed by Professor Eduardo Zilberman and Professor Pedro Cavalcanti Ferreira, for very useful commentary and criticism.

I must also mention two friends who were of great support during these two hard years: Murilo Ramos and Josue Cox. I learned to hold you two in the highest esteem and see you like brothers to me. I truly miss the time I spent and conversations I had with you two. I just wish we could have spent easier days together.

To Gustavo Joaquim and Felipe Alves, I must say that this couple of years living together was not the easiest, but I recognize your help in sharing the apartment with me and the times you had to put up with my difficulties. I also acknowledge your advice and guidance when I most needed them. I am very indebted to you guys.

Last but not least, I am thankful for the financial support provided by the CNPq. After all, there is no such thing as a free lunch. 


\section{Abstract}

Mazin, Felipe Ruiz; Carvalho, Carlos Viana de (Advisor). Dissecting Chimerica: A Structural Decomposition of Global Imbalances. Rio de Janeiro, 2014. 62p. Dissertação de Mestrado - Departamento de Economia, Pontifícia Universidade Católica do Rio de Janeiro.

In a speech to the Federal Reserve Board in 2005, chairman Ben Bernanke put forth the hypothesis of a Global Saving Glut to explain the recurring American current account deficits. According to him, the world was experiencing an excess of desired savings over desired investment, which drove capital flows to the United States and reduced global real interest rates. Building on the framework of Gertler (1999) and Ferrero (2010), this paper provides a structural decomposition of global capital flows in a 3country global economy model with imperfect capital mobility, including the United States, the rest of the rich economies, and China. I find that differences in the stage of the demographic transition of each region and in social security systems help explain the flow of capital from China to the United States, compensating the differences in productivity growth, which would drive the flow in the opposite direction.

\section{Keywords}

Global Imbalances; Productivity Growth; Demographic Trends; Social Security; Costs of Portfolio; 


\section{Resumo}

Mazin, Felipe Ruiz; Carvalho, Carlos Viana de. Dissecando

Chimerica: Uma Decomposição Estrutural de Desequilíbrios Globais. Rio de Janeiro, 2014. 62p. Dissertação de Mestrado - Departamento de Economia, Pontifícia Universidade Católica do Rio de Janeiro.

Em um discurso para o Conselho do Federal Reserve em 2005, o presidente Ben Bernanke propôs a hipótese do Excesso de Poupana Global para explicar os déficits recorrentes na conta corrente americana. De acordo com ele, o mundo estava passando por um excesso de poupança desejada sobre investimento desejado, o que levou fluxos de capital aos Estados Unidos e reduziu as taxas reais de juros globais. Baseando-se nos modelos de Gertler (1999) e Ferrero (2010), esse trabalho apresenta uma decomposição estrutural dos fluxos de capitais globais em um modelo de economia global com três países e com mobilidade imperfeita de capitais, incluindo Estados Unidos, o resto das economias ricas e China. Eu encontro que diferenças nos estágios da transição demográfica e nos sistemas de previdência social de cada região ajudam a explicar o fluxo de capitais da China para os Estados Unidos, compensando as diferenças de crescimento da produtividade, que direcionariam o fluxo no sentido oposto.

\section{Palavras-chave}

Desequilíbrios Globais; Crescimento de Produtividade; Tendências Demográficas; Previdência Social; Custos de Portfólio; 


\section{Contents}

1 Introduction $\quad 8$

2 Literature 10

3 Model description $\quad 12$

$\begin{array}{lll}3.1 & \text { Demography } & 12\end{array}$

3.2 Agents 13

$\begin{array}{lll}3.3 & \text { Firms } & 20\end{array}$

3.4 Government 20

3.5 Assets and Balance of Payments 21

4 Quantitative Analysis $\quad 23$

4.1 Calibration 23

4.2 Quantitative Results 30

4.3 The Decline in Real Interest Rates 36

$\begin{array}{lll}5 & \text { Conclusion } & 39\end{array}$

6 Bibliography $\quad 41$

A Analytical Appendix $\quad 44$

A.1 Solution for agents' problems 44

A.2 Aggregation $\quad 53$

A.3 Human Wealth and Social Security Value 55

$\begin{array}{ll}\text { A.4 Firm's problem } & 57\end{array}$

B Statistical Appendix $\quad 59$

C Alternative Series for TFP $\quad 62$ 


\section{Introduction}

The former chairman of the Federal Reserve, Ben Bernanke, in a speech to the Board of Governors in 2005 (Bernanke, 2005), presented the hypothesis of a Global Saving Glut (GSG) in order to help explain the recent deterioration of the United States current account. According to him, the GSG is a global phenomenon due to events in developed as well as developing countries. Among its main causes one can find demographic factors, surge in oil prices and policy changes in emerging economies. The glut led to a mismatch between desired savings and desired investment, which drove down real interest rates in the G7 economies, from an average of $6 \%$ in the late 1990s to less than $1 \%$ in the wake of the financial crisis (see Figure (1.1(a))).

The Unites States, which presented the safest options for investment in its bond and equity markets, absorbed this excess of savings, and as a result, started to experience successive and increasing current account deficits. Figure (1.1(b)) shows that the country's deficit reached a peak of $5.76 \%$ of the GDP in 2006, subsiding thereafter in the wake of the financial crisis. The most emblematic relationship of the period was the one between the United States and China, its biggest creditor. The economic historian Niall Ferguson dubbed this relationship Chimerica back in 2007 (Ferguson, 2007), a play on the words America, China and Chimera, the Greek mythological creature ${ }^{1}$.

Despite acknowledging the phenomenon, Bernanke and Ferguson were not able to foresee the implications of such imbalances. It is argued that once the glut pulled down interest rates, the financial industry had to come up with new instruments to quell investors' craving for high returns. This gave rise to all the complex and opaque assets that triggered the crisis.

The fact that countries like China have high saving rates is not a recent phenomenon, though. While U.S. net savings rates hardly reach $10 \%$ of the gross national income, Chinese rates have been on the double digits since there is record. The Chinese net saving rate in 2012 was $41.7 \%$ of the GNI, while the American rate was negative, $-2.4 \%$ of the $\mathrm{GNI}^{2}$. Since the seminal work of Feldstein (1974) much has been discussed about the effects of pension systems on private savings. The available evidence points toward the idea that social

\footnotetext{
${ }^{1}$ Chimera was an animal composed by parts of a lion, a goat and a snake. The term has come to mean anything that is made by strikingly different parts or is rather imaginative, devoid of reality.

${ }^{2}$ Numbers from the World Development indicators database
} 
(1.1(A)) Real interest rates

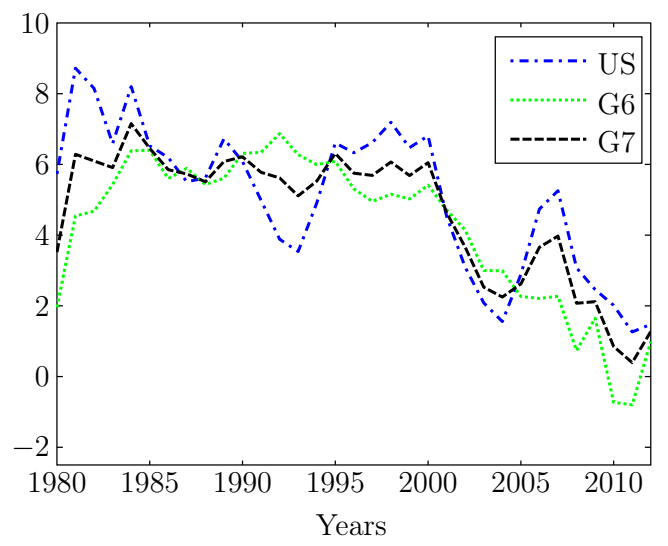

(1.1(B)) U.S. Current Account Balance (\% GDP)

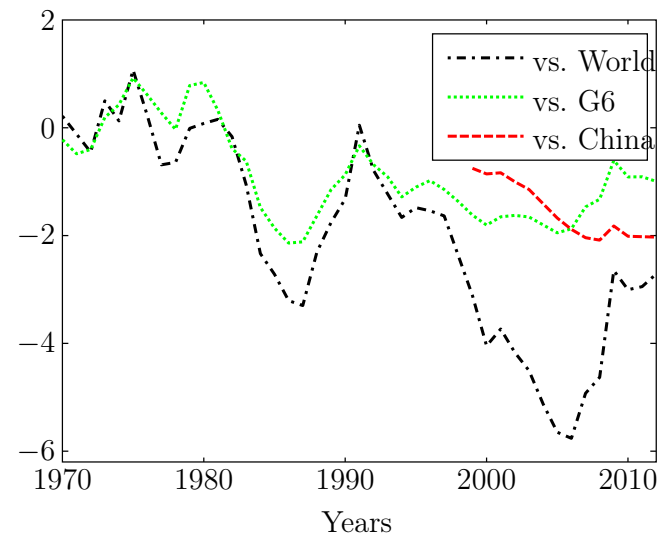

security systems tend to crowd them out.

The goal of this study is to break down the Chimerica relationship structurally and assess how much differences in social security systems can influence consumption and savings behaviour in different countries and thus account for international imbalances. The analysis will focus on basically three possible driving forces behind the emergence of the glut: demographics and its effects through different social security systems, fiscal policy and productivity. The method consists in running counterfactual simulations in order to gauge the extent to which each force contributes to the phenomenon. Dividing the world economy in three regions: United States, the rest of the G7 (Canada, France, Germany, Italy, Japan and United Kingdom, henceforth G6) and China, the analysis employs a 3-country overlapping generations (OLG) model with time-varying exogenous variables.

The results point that differences in social security systems coupled with the demographic transition can very well explain the high saving rates in China. This leads to the "unnatural" direction of capital flows towards the United States: the Chimerica relationship. These differences compensate the differentials in productivity that would drive capital in the opposite direction. Fiscal policy accounts for just a small portion of the imbalances.

Section 2 sets the position of this paper in the literature, Section 3 introduces the overlapping generations (OLG) model chosen to assess this question, Section 4 discusses the implementation and results and Section 5 concludes the paper. 


\section{2 \\ Literature}

This paper builds heavily upon Ferrero (2007) and Ferrero (2010), who develops a structural decomposition for the U.S. trade balance versus the other countries of the G7 in a two-country model. Ferrero, in his turn, extends the closed economy model of Gertler (1999). He finds that the American trade balance's fluctuations can be almost entirely explained by differentials in productivity growth and that demographic factors constitute a non-negligible and permanent aspect in explaining the deficits. He notes on the conclusion, however, that this decomposition probably does not hold for the trade balances against developing economies, since the model would predict these fast growing economies to attract capital flows (this is the socalled Lucas paradox, see Lucas (1990)). By doing an exercise with China, he finds counterfactual results.

In a sense, this paper seeks to redo the exercise and makes two important departures. The first is that it adds some friction in global capital markets and assumes imperfect capital mobility so as to control the degree of openness of China, a country that has been gradually introduced to the global markets for the last decades. The second difference is the modelling of different social security systems in order to investigate how much these institutional differences can account for the imbalances between the United States and China.

This paper can be grouped with studies that focus on capital flows between developed countries and that take into account demographic factors, such as Feroli (2003), which studies the balances among the G7 nations, and Henriksen (2002), which investigates the contribution of demographic factors in explaining U.S.-Japan bilateral capital flows. However, the analysis here has more similarities with studies of multiregion OLG models that include developing nations, such as Brooks (2003) and Attanasio, Kitao and Violante (2006). These papers study the capacity of diverging demographic factors explaining the long run trends in capital flows among nations.

Attanasio, Kitao and Violante (2007) apply their two-region OLG model in order to study the sustainability of social security systems in rich countries who are witnessing the end of the ageing process of their population. Fehr, Jokish and Kotlikoff (2005) employ a reasonably complex model to study future paths of demographic, fiscal and economic transition paths for the developed world plus China. Their analyses, however, use only 
two benchmarks: closed or perfectly open economies. Moreover, the usage of only these two benchmarks is the norm in all studies of capital flows. This paper also proposes a new model to establish a continuum of openness between economies.

With respect to my main result, this paper can be thought as a empirical analysis of the question tackled theoretically by Eugeni (2013). She derives the conditions under which an excess of savings may emerge in a developing country that does not have a social security system in an open life-cycle economy à la Diamond (1965). 


\section{3}

\section{Model description}

This is an N-country OLG deterministic model with portfolio adjustment costs. The model is an extended version of the two-country model of Ferrero (2010), which in turn extends the model of Gertler (1999). The idea is to nest the model of Ferrero by extending the number of regions and by defining a cost parameter that controls the level of openness of each economy: the higher the cost, the more closed the economy in question is. The goal is to establish a general framework in order to apply it to the case of a setting of three countries: the United States (US), the G6 and China.

\section{1}

\section{Demography}

The set of countries is defined as $\Theta \equiv\{1, \ldots, N\}$. Since this is a lifecycle economy, individuals in each country $m \in \Theta$ have finite lives divided into two periods: working age $(w)$ and retirement $(r)$. These individuals are already born workers and each period remain workers for next period with a probability $\omega_{m}$, that is, their average time in labor force is given by $1 /\left(1-\omega_{m}\right)$. The mass of workers at $t$ is given by $N_{m t}^{w}$ and produces $\left(1+n_{m t, t+1}-\omega_{m}\right) N_{m t}^{w}$ new workers at the following period, thereby leading to the law of motion for the labor force:

$$
N_{m t+1}^{w}=\left(1-\omega_{m}+n_{m t, t+1}\right) N_{m t}^{w}+\omega N_{m t}^{w}=\left(1+n_{m t, t+1}\right) N_{m t}^{w}
$$

The labor force thus grows at a rate $n_{m t, t+1}$ from period $t$ to period $t+1$. As soon as a worker flips into retirement, he or she survives from period $t$ to period $t+1$ with a probability of $\gamma_{m t, t+1}$, as in Blanchard (1985), implying an average time in retirement of $1 /\left(1-\gamma_{m t, t+1}\right)$. Expressing the mass of retirees at period $t$ by $N_{m t, t+1}^{r}$, it therefore evolves according to:

$$
N_{m t+1}^{r}=\left(1-\omega_{m}\right) N_{m t}^{w}+\gamma_{m t, t+1} N_{m t}^{r}
$$

The dependency ratio, $\psi_{m t}$, is defined as the number of retirees per worker: how many retirees depend on one worker. It can be seen as an indicator not so much of the aging of the population, since social security reforms on the age of retirement can change it, but more as an indicator of the sustainability of the social security system (in the case of a pay-as-you-go system). Given the laws of motion above, it can be shown to evolve according to: 


$$
\left(1+n_{m t, t+1}\right) \psi_{m, t+1}=\left(1-\omega_{m}\right)+\gamma_{m t, t+1} \psi_{m t}
$$

When it comes to maximize their utility, workers and retirees face different problems. Their optimal decisions are derived below.

\section{2}

\section{Agents}

The economy is composed by a single good, the numeraire, which is consumed by both types of agents. Agents decide then how much to consume each period from their budget. They have their preferences modeled by the following version of the recursive non-expected utility family (Epstein and Zin, 1989):

$$
V_{m t}^{z}=\max \left[\left(C_{m t}^{z}\right)^{\rho}+\beta_{m t, t+1}^{z} \mathbb{E}_{t}\left[V_{m, t+1} \mid z\right]^{\rho}\right]^{\frac{1}{\rho}}
$$

Where $z$ represents the agent's type: $z=w, r$. $V_{m t}^{z}$ represents the value of utility of an agent of type $z$ at time $t$ and $C_{m t}^{z}$ his or her consumption in $z$. The discount factor $\beta_{t, t+1}^{z}$ is lower and varies through time for retirees, since they have to account for their probability of death, which varies according to life expectancy.

This particular sort of preferences allows the separation of the coefficient of elasticity of substitution from the one of risk aversion, thereby making it possible to assume risk neutrality with respect to income fluctuations (Farmer, 1990), which otherwise would have been unfeasible. This is necessary because the source of income risk here is an artificial assumption of a probability of retiring and the adoption of standard preferences would lead to a great rate of savings for young individuals, which is at odds with the data.

The extension of this model resides in agents' budget constraints. Since this setting allows the modeling of a global economy, not only will agents choose how much to consume out of their budget, but also where to invest their savings, that is, how to allocate their portfolio.

\subsection{1}

\section{Retirees}

Once an agent retires he will have two sources of income: their social security payments and the interest income that accrues from their invested assets. Following Yaari (1965), Blanchard (1985) and Gertler (1999), I abstract from the impact of the risk of an uncertain time of death and insure all retirees against it. The motive is that not taking this into account may pose problems to the derivation and aggregation of individual decision rules. In the case of 
workers, though, the restriction is made on preferences instead of on the budget constraint.

This insurance is provided by assuming the existence of a mutual fund for each country which invests the wealth from all retirees of that country and on the following period returns the proceeds to each surviving agent proportionate to his or her initial contribution. Therefore, the gross rate of return from last period for a retiree in country $m$ on assets from some country $\ell, R_{\ell t-1}$, will be adjusted by the mortality probability of last period, $\gamma_{m t-1, t}$, which will represent, on average, the share of retirees who survived and made it to the current period. By doing this, retirees are completely insured against the risk of death.

In addition, following Chang, Liu and Spiegel (2013), agents in country $m$ will incur on portfolio costs at each period depending on the share of each country's assets in their portfolio. This cost will increase quadratically with the difference of each share from a pre-established level, which will be denoted by $\bar{\eta}_{m \ell}$, for assets from some country $l$. The parameter that captures the magnitude of this cost will be specific to each pair of countries and also to which of the two countries the agent is from. This parameter will be represented by $\Lambda_{m \ell}$, which is the parameter that adjusts the cost an agent in country $m$ will have when holding country $\ell$ 's assets.

It is important to note here that this formulation is simply a reduced form whereby a myriad of factors that gives rise to different real interest rates across countries-even after controlling for differences in risk premia-will be captured in only one parameter, $\Lambda_{m \ell}$. By adjusting this parameter, it is possible to create a continuum of the degree of openness of each country, with, at one end, a totally closed economy, and, at the other end, a setting with perfect capital mobility.

Given the discussion above, it is now possible to properly define the problem of the retiree of this economy. A retiree born in country $m$ in period $j$ and retired at period $k$ will have as sources of his or her budget, social security payments, $E_{m t}^{r j k}$, interest income and also the assets he or she can immediately sell in the international markets. He or she will then choose the amount to consume out of his or her wealth, $C_{m t}^{r j k}$, and on which assets to invest the rest, $\left\{A_{m \ell t}^{r j k}\right\}_{\ell \in \Theta}$, making this a portfolio allocation problem. The budget constraint this retiree will face is thus given by:

$$
C_{m t}^{r j k}+\left(1+\sum_{\ell \neq m} \frac{\Lambda_{m \ell t}}{2}\left(\eta_{m \ell t}^{r j k}-\bar{\eta}_{n m}\right)^{2}\right) \sum_{\ell \in \Theta} A_{m \ell t}^{r j k}=\frac{1}{\gamma_{m t-1, t}} \sum_{\ell \in \Theta} R_{\ell t-1} A_{m \ell t-1}^{r j k}+E_{m t}^{r j k}
$$


where $\eta_{m p t}^{r j k} \equiv A_{m p t}^{r j k} / \sum_{\ell \in \Theta} A_{m \ell t}^{r j k}$ for some country $p$ is the share of country $p$ 's assets in a portfolio of a retiree from country $m$, and the term between brackets on the left-hand side represents the cost of portfolio the retiree will incur when holding shares different from the pre-established levels.

From equation (3-4), we can determine the exact form of the retiree's value function and maximization problem simply by noting that $\beta_{m t, t+1}^{r}=$ $\gamma_{m t, t+1} \beta$, where $\beta$ is the constant discount factor that represent agents' time preferences per se and $\gamma_{m t, t+1}$ accounts for the probability of surviving for next period.

$$
V_{m t}^{r j k}=\max _{C_{m t}^{r j k},\left\{A_{m \ell t}^{r j k}\right\}_{m \in \Theta}}\left[\left(C_{m t}^{r j k}\right)^{\rho}+\gamma_{m t, t+1} \beta\left(V_{m t+1}^{r j k}\right)^{\rho}\right]^{\frac{1}{\rho}}
$$

subject to $(3-5)$.

The solution to this intertemporal optimization problem will lead to $N$ policy functions, one for consumption and the rest for each type of asset. However, since we are dealing with a potentially ever-increasing labor force and labor-augmenting productivity, as it will be seen below, the variables for consumption and assets are potentially non-stationary. The way to get around this is to find $N$ stationary variables that pin down the non-stationary variables. One variable will be the marginal propensity to consume out of wealth $(\mathrm{mpcw})$, which will determine the share of wealth consumed by each retiree at each period, and the rest $N-1$ variables are the shares of savings that will be invested in assets of each of the $N$ countries.

Considering the amount invested in country $m$ 's assets as residual, the $N-1$ policy functions with regard to the amount invested in each asset are:

$$
A_{m p t}^{r j k}=\eta_{m p t}^{r j k} \sum_{\ell \in \Theta} A_{m \ell t}^{r j k}
$$

for $p \neq m$. The share invested in assets of country $p \neq m, \eta_{m p t}^{r j k}$, can be shown to be given by:

$$
\left(1+\sum_{\ell \neq m} \frac{\Lambda_{m \ell t}}{2}\left(\eta_{m \ell t}^{r}-\bar{\eta}_{m \ell}\right)^{2}\right)\left(R_{p t}-R_{m t}\right)=\Lambda_{m p t}\left(\eta_{m p t}^{r}-\bar{\eta}_{m p}\right) R_{m t}
$$

Note that the law of motion for $\eta_{m p t}^{r}$ is identical for every retiree, regardless of his age of birth or retirement. For that reason superscripts $j$ and $k$ are dropped. The solution of the worker's problem will yield the same condition as it will be seen below and superscript $r$ will be dropped as well. The remainder policy function is for consumption and its guess is the following: 


$$
C_{m t}^{r j k}=\varepsilon_{m t}^{j k} \pi_{m t}^{j}\left(\frac{1}{\gamma_{m t-1, t}} \sum_{\ell \in \Theta} R_{m t-1} A_{m \ell t-1}^{r j k}+S_{m t}^{r j k}\right)
$$

where $\varepsilon_{m t}^{j k} \pi_{m t}^{j}$ is the marginal propensity to consume out of wealth for a retiree born in $j$ and retired at $k, S_{m t}^{r j k}$ is the discounted sum of their future pension income, $\left\{E_{m t+v}^{r j k}\right\}_{v=0}^{\infty}$, and is better defined at Section A.1.1 of the appendix. The solution of this problem ${ }^{1}$ will result in the following nonlinear difference equation for the law of motion for the retiree's mpcw:

$$
\varepsilon_{m t} \pi_{m t}=1-\gamma_{m t, t+1} \beta^{\sigma}\left(\frac{\sum_{m \in \Theta} \eta_{m \ell t}^{r} R_{m t}}{1+\sum_{\ell \neq m} \frac{\Lambda_{m \ell t}}{2}\left(\eta_{m \ell t}^{r}-\bar{\eta}_{m \ell}\right)^{2}}\right)^{\sigma-1} \frac{\varepsilon_{m t} \pi_{m t}}{\varepsilon_{m t+1} \pi_{m t+1}}
$$

Once again, note that the equation above holds for all retirees, and thus the superscripts are dropped from $\varepsilon_{m t} \pi_{m t}$. The retiree's problem will therefore yield $N$ equations that will be part of the final system of equations.

\section{2 .2}

\section{Workers}

Compared to the retiree's problem, the worker's problem presents some differences. First, with regard to their budget constraint, a worker born in country $m$ in period $j$ will work and supply inelastically one unit of labor per period $t$, thereby receiving a wage $W_{m t}^{w j}$. Moreover, in this economy only workers are required to pay taxes, $T_{m t}^{w j}$, in order to finance government expenditures and pension payments as it will be seen below. This implies that the social security system in this economy is what is known as a pay-as-you-go system, a system where current receipts, paid as taxes, are used to pay current benefits. Besides those two points and the fact that there is no mutual fund in this case, workers' budget constraint is the same as retirees'. A worker born in period $j$ has the following budget constraint:

$C_{m t}^{w j}+\left(1+\sum_{\ell \neq m} \frac{\Lambda_{m \ell t}}{2}\left(\eta_{m \ell t}^{w j}-\bar{\eta}_{n m}\right)^{2}\right) \sum_{\ell \in \Theta} A_{m \ell t}^{w j}=\sum_{\ell \in \Theta} R_{\ell t-1} A_{m \ell t-1}^{w j}+W_{m t}^{w j}-T_{m t}^{w j}$

where $\eta_{m p t}^{w j} \equiv A_{m p t}^{w j} / \sum_{\ell \in \Theta} A_{m \ell t}^{w j}$ is the share of country $p$ 's assets in a worker from country $m$ 's portfolio. With respect to the value function and the worker's optimization problem, the expected value of the next period's value function

${ }^{1}$ The derivation can be found in Section A.1.1 in the appendix.

${ }^{2}$ All workers receive the same wages and pay the same taxes, the superscript $j$ only denotes that this is the amount each worker receive individually, as opposed to the notation for aggregate wages and taxes, which lack this superscript. 
will have to take into consideration the probabilities of the worker remaining in the labor force and of he or she flipping into retirement. Therefore, the problem can be written as:

$$
V_{m t}^{w j}=\max _{C_{m t}^{w j},\left\{A_{m \ell t}^{w j}\right\}_{m \in \Theta}}\left[\left(C_{m t}^{w j}\right)^{\rho}+\beta\left(\omega_{m} V_{m t+1}^{w j}+\left(1-\omega_{m}\right) V_{m t+1}^{r j t+1}\right)^{\rho}\right]^{\frac{1}{\rho}}
$$

subject to (3-11). Recall that $\omega_{m}$ is the probability of a worker remaining in the labor force from period $t$ to period $t+1$. As with the other problem, the solution will involve $N$ policy functions. The $N-1$ policy functions that give the amount invested in each type of asset, as in the case of retirees, are given by:

$$
A_{m p t}^{w j}=\eta_{m p t}^{w j} \sum_{\ell \in \Theta} A_{m \ell t}^{w j}
$$

for $p \neq m$. Solving the problem, however, will show that the shares of each country's assets in the worker's portfolio will be given by the same condition as in the previous case. Thus, in the case of variables $\eta_{m \ell t}$ for $m, \ell \in \Theta$, superscripts can be dropped. Therefore equation (3-8) can be rewritten as:

$$
\left(1+\sum_{\ell \neq m} \frac{\Lambda_{m \ell t}}{2}\left(\eta_{m \ell t}-\bar{\eta}_{m \ell}\right)^{2}\right)\left(R_{p t}-R_{m t}\right)=\Lambda_{m p t}\left(\eta_{m p t}-\bar{\eta}_{m p}\right) R_{m t}
$$

for any $p \neq m$.

The guess for the consumption function will have the same form as in the retirees' problem:

$$
C_{m t}^{w j}=\pi_{m t}^{j}\left(\sum_{\ell \in \Theta} R_{\ell t-1} A_{m \ell t-1}^{w j}+H_{m t}^{w j}+Z_{m t}^{w j}\right)
$$

where $\pi_{m t}$ is the mpcw of each worker and $H_{m t}^{w j}$ is the amount of the worker's human wealth at $t$ and $Z_{m t}^{w j}$ is the value of their future social security payments at the current period. Human wealth is defined as the sum of all future wage earnings after taxes discounted by future real interest rates adjusted by the future probabilities of remaining in the labor force and also by the future portfolio costs. The value of future social security payments for workers is the sum of future pension payments discounted by the adjusted interest rate. The precise definitions can be found in Section A.3 of the appendix. It can be shown that $\pi_{m t}$ moves according to the following rule of motion (for every worker, that is why the superscript $j$ is dropped): 


$$
\pi_{m t}=1-\beta^{\sigma}\left(\frac{\Omega_{m t+1} \sum_{\ell \in \Theta} \eta_{m \ell t} R_{\ell t}}{1+\sum_{\ell \neq m} \frac{\Lambda_{m \ell t}}{2}\left(\eta_{m \ell t}-\bar{\eta}_{m \ell}\right)^{2}}\right)^{\sigma-1} \frac{\pi_{m t}}{\pi_{m t+1}}
$$

where:

$$
\Omega_{m t+1} \equiv \omega_{m}+\left(1-\omega_{m}\right) \varepsilon_{m t+1}^{\frac{1}{1-\sigma}}
$$

Since the $N-1$ equations that determine the shares of each country's assets in agents' portfolio are identical in the case of retirees as in the case of workers, the workers' problem will only add equations (3-16) and (3-17) to the final system of equations.

\subsection{3}

\section{Aggregating agents}

What remains to be done with respect to the behavior of agents is aggregating consumption and some variables defined before only at the individual level. Starting first with consumption, which is a key variable to understand the behavior of consumers, total consumption will be given by the sum of total consumption by retirees and by workers.

$$
C_{m t} \equiv C_{m t}^{w}+C_{m t}^{r}
$$

where

$$
C_{m t}^{r}=\varepsilon_{m t} \pi_{m t}\left(\sum_{\ell \in \Theta} R_{\ell t-1} A_{m \ell t-1}^{r}+S_{m t}\right)
$$

and

$$
C_{m t}^{w}=\pi_{m t}\left(\sum_{\ell \in \Theta} R_{\ell t-1} A_{m \ell t-1}^{w}+H_{m t}+Z_{m t}\right)
$$

where $A_{m p t}^{r} \equiv \sum_{r} A_{m p t}^{r j k}$ and $A_{m p t}^{w} \equiv \sum_{w} A_{m p t}^{w j}$ are the total amount of assets of each country $p \in \Theta$ held by retirees and workers, respectively. Variables $S_{m t}$, $H_{m t}$ and $Z_{m t}$ are simply the values of $S_{m t}^{r}, H_{m t}^{w}$ and $Z_{m t}^{w}$ summed across all retirees and workers and are given by:

$$
S_{m t}=N_{m t}^{r} S_{m t}^{r} \quad H_{m t}=N_{m t}^{w} H_{m t}^{w} \quad Z_{m t}=N_{m t}^{w} Z_{m t}^{w}
$$

This follows from the fact that pension payments are paid equally to retirees, and that wages and taxes are paid equally to and by workers, respectively. This leads to every retiree or worker valuing identically their current and future social security payments and to every worker valuing equally 
their current and future labor income after taxes, which make up their human wealth. The recursive formulas for each of these three variables have to be adjusted then by the rate of population growth and can be found in Section A.3 of the appendix.

Defining $\lambda_{m t}$ as the share of total retirees's wealth in total wealth, $\lambda_{m t} \equiv A_{m t}^{r} /\left(A_{m t}^{w}+A_{m t}^{r}\right)=A_{m t}^{r} / A_{m t}$, where $A_{m t}^{z} \equiv \sum_{\ell \in \Theta} A_{m \ell t}^{z}$, it is possible to rewrite (3-18) as:

$$
C_{m t}=\pi_{m t}\left[\left(1-\left(1-\varepsilon_{m t}\right) \lambda_{m t-1}\right) \sum_{\ell \in \Theta} R_{\ell t-1} A_{m \ell t-1}+\varepsilon_{m t} S_{m t}+H_{m t}+Z_{m t}\right]
$$

The formula for total consumption, (3-22), together with the definitions for $S_{m t}, Z_{m t}$ and $H_{m t}$ summarizes how Ricardian equivalence is broken in this framework and the impact of fiscal policy and social security on aggregate consumption, savings and external imbalances. As the definition shows, agents discount future at a higher rate than does the government ${ }^{3}$, thus, any expansionary policy financed by future tax increases have a positive impact on consumption demand. Furthermore, pension payments, which is an intragenerational and intratemporal redistribution of resources, lead to increased consumption demand, since retirees have a higher marginal propensity to consume than workers. Therefore an increase in taxes in $t$ to finance social security, $\Delta T_{m t}=\Delta E_{m t}$, will have a negative impact on workers' consumption, $\pi_{m t} \Delta T_{m t}$, but a more than proportional positive impact on retirees' consumption, $\epsilon_{m t} \pi_{m t} \Delta E_{m t}$.

Lastly, the share of retiree's assets in total assets, $\lambda_{m t}$, can then be shown to follow the law of motion below (derivation in Section A.2 of the appendix):

$$
\begin{array}{r}
\lambda_{m t}=\left(1-\omega_{m}\right)+\frac{\omega_{m}}{1+\sum_{\ell \neq m} \frac{\Lambda_{m \ell t}}{2}\left(\eta_{m \ell t}-\bar{\eta}_{m \ell}\right)^{2}}\left(\left(1-\varepsilon_{m t} \pi_{m t}\right) \lambda_{m t-1} \times\right. \\
\left.\times \frac{\sum_{\ell \in \Theta} R_{\ell t-1} A_{m \ell t-1}}{A_{m t}}+\frac{E_{m t}-\varepsilon_{m t} \pi_{m t} S_{m t}}{A_{m t}}\right)
\end{array}
$$

This last equation closes the agents section. Next section deals with the representative firm's problem.

\footnotetext{
${ }^{3}$ The weighted interest rate adjusted by the portfolio cost does not deviate too much from the domestic rate, since when interest rates differ by a great margin, it is because of high costs in holding other country's assets
} 


\section{3}

\section{Firms}

Firms in this economy will be represented by a single firm which operates in perfectly competitive input and output markets. It will hire workers and accumulate capital in order to produce the single good of this economy. The production function is assumed to exhibit constant returns to scale and technology to be labor-augmenting. The labor share is identical across countries:

$$
Y_{m t}=\left(X_{m t} N_{m t}^{w}\right)^{\alpha} K_{m t-1}^{1-\alpha}
$$

Technology is assumed to grow exogenously at a rate $x_{m t, t+1}$ between periods $t$ and $t+1$ :

$$
X_{m t+1}=\left(1+x_{m t, t+1}\right) X_{m t}
$$

The law of motion of capital will be augmented by quadratic adjustment costs with respect to changes in investment. This additional feature has the objective of smoothing out the trajectory of investment through time in order to match the data.

$$
K_{m t}=(1-\delta) K_{m t-1}+\left(1-\frac{\phi}{2}\left(\frac{I_{m t}}{I_{m t-1}}-\left(1+n_{m t-1, t}+x_{m t-1, t}\right)\right)^{2}\right) I_{m t}
$$

where $\delta$ is the depreciation rate and $\phi$ is the parameter that calibrates the adjustment costs, both are held constant across countries. The term $\left(1+n_{m t-1, t}+x_{m t-1, t}\right)$ represents the rate of growth of investment in the long run. The firm's problem then becomes dynamic once it has to account for adjustment costs in its investment decisions. Its solution can be found in Section A.4 of the appendix.

\section{4}

\section{Government}

At each period the government issues one-period bonds, $\Delta B_{m t}$, levies lump-sum taxes on workers, $T_{m t}$ and receives the total amount of costs foreigners pay for holding a share of the country's assets, just as if it were a tax on foreign capital. With these resources, it pays lump-sum pension transfers to retirees, $E_{m t}$, pays interest to bondholders, $\left(R_{m t-1}-1\right) B_{m t-1}$, and finances wasteful spending, $G_{m t}$. Therefore, at each period the government must satisfy the budget constraint: 
$G_{m t}+\left(R_{m t-1}-1\right) B_{m t-1}+E_{m t}=\Delta B_{m t}+T_{m t}+\sum_{\ell \neq m}\left(\frac{\Lambda_{\ell m t}}{2}\left(\eta_{\ell m t}-\eta_{\ell m}\right)^{2} \sum_{k \in \Theta} A_{\ell k t}\right)$

All variables are assumed to be exogenous, except for $T_{m t}$, which will be determined endogenously so that the constraint holds each period. All these variables will be given as a ratio to the GDP. Thus,

$$
G_{m t}=g_{y} Y_{m t} \quad B_{m t}=b_{m t} Y_{m t} \quad E_{m t}=e_{m t} Y_{m t} \quad T_{m t}=\tau_{m t} Y_{m t}
$$

Note that three ratios are given exogenously, being one time and countryinvariant, $g_{y}$, and the other two are allowed to vary across countries and through time, $b_{m t}$ and $e_{m t}$. The tax burden, $\tau_{m t}$, is given endogenously, as pointed out above.

\section{5}

\section{Assets and Balance of Payments}

Total assets for country $m \in \Theta$ will be composed by its physical capital and its government bonds. However, agents will be able to hold assets from other countries, and that must be taken into account. Thus, the amount of assets agents from a country $m$ possess from their own country, $A_{m m t}$, is given by:

$$
A_{m m t}=K_{m t}+B_{m t}-F_{m t}
$$

where $F_{m t}$ stands for the amount of this capital and debt that is held by foreign investors. This variable can therefore be written as:

$$
F_{m t} \equiv \sum_{\ell \neq m} A_{\ell m t}=\sum_{\ell \neq m} \eta_{\ell m t} A_{\ell t}
$$

The definition of another variable will help close the definitions of all asset positions. Defining $D_{m t}$ as the amount of foreign countries' assets held by residents of country $m$ :

$$
D_{m t} \equiv \sum_{\ell \neq m} A_{m \ell t}=\left(1-\eta_{m m t}\right) A_{m t}
$$

The net foreign asset position, $\mathcal{F}_{m t}$, is defined as the difference between the gross foreign asset position, $D_{m t}$, and the claims foreign investors have over national assets, $F_{m t}$ :

$$
\mathcal{F}_{m t} \equiv D_{m t}-F_{m t}
$$


The balance of payments identity states that a current account deficit (surplus) must be counterbalanced by a capital account suplus (deficit). In terms of the model in question, we have:

$$
N X_{m t}+\text { Income Account }_{m t}=\Delta \mathcal{F}_{m t}
$$

where $N X_{m t}$ is country $m$ 's net exports at period $t$. This variable will be given residually in the model as the difference between production, $Y_{m t}$, and absorption, $C_{m t}+I_{m t}+G_{m t}$. The income account balance in period $t$ is given by the interest payments accruing to domestic residents from foreign investments minus the payments accruing to foreigners from domestic investments:

$$
\text { Income Account }_{m t}=\sum_{\ell \neq m}\left(R_{\ell t-1}-1\right) \eta_{m \ell t} A_{\ell t-1}-\left(R_{m t-1}-1\right) F_{m t-1}
$$

Therefore, from (3-34) and (3-33), the law of motion of the net foreign asset position can be written as:

$$
\mathcal{F}_{m t+1}=\mathcal{F}_{m t}+\sum_{\ell \neq m}\left(R_{\ell t-1}-1\right) \eta_{m \ell t} A_{\ell t-1}-\left(R_{m t}-1\right) F_{m t-1}+N X_{m t}
$$

Finally, all net foreign asset positions must necessarily add up to zero in equilibrium:

$$
\sum_{m \in \Theta} \mathcal{F}_{m t}=0
$$

The definition of a equilibrium in this economy can now be defined:

\section{Definition.}

A competitive equilibrium in the open economy with imperfect capital mobility is a sequence of endogenous quantities and prices that:

$i$ solve households' intertemporal maximization of utility problem;

ii solve firms' inter temporal maximisation of profits problem;

iii satisfy the government budget constraint and;

iv clear all markets, given the paths of the exogenous variables $\left\{\left\{n_{m t-1, t}, x_{m t-1, t}, \gamma_{m t-1, t}, b_{m t}, e_{m t},\left\{\Lambda_{m p t}\right\}_{p \neq m}\right\}_{t=0}^{T}\right\}_{m \in \Theta}$. 


\section{4 \\ Quantitative Analysis}

This section discusses the quantitative exercise employed to decompose structurally the global economic transactions among the United States, the G6 countries and China from 1970 through 2012. More specifically, the goal is to analyze how much the calibrated model can account for the observed patterns of global imbalances and thus evaluate the effect of differentials in productivity, demographics, fiscal policy and social security system on the result.

I find that differences in social security systems coupled with the demographic transition can very well explain the high saving rates in China. This leads to capital flowing out of China and into the United States: the Chimerica relationship. These differences compensate the differentials in productivity that would drive capital in the opposite direction. I also find that fiscal policy accounts for just a small portion of the imbalances.

\section{1}

\section{Calibration}

The calibration for the parameters can be found in Table (4.1). The elasticity of intertemporal substitution, $\sigma$, is chosen to reflect micro-estimates. The labor share, $\alpha$, assumes a value fairly standard in real business cycle models. The ratio of government expenditures to GDP, $g_{y}$, is chosen to be constant, since for all countries in the G7, except for Japan, the ratio is roughly constant and hovers around 20\%. As for China, the ratio fluctuates a bit, however, to abstract from this dimension of fiscal policy, it is also kept at $20 \%$. The depreciation rate $\delta$ is set at 0.1 . The parameter $\beta$, which represents agents' time preferences, is set to imply a real interest rate of approximately $5 \%$ per year in 1970 . The investment adjustment cost, $\phi$, is determined so as to roughly match the volatility of the series of current account observed in the data. Finally, the parameters $\bar{\eta}_{m p}$ for any $m$ and $p$ are all set equal to zero, so that the parameter that calibrates portfolio adjustment costs, $\Lambda_{m p t}$, can be understood as the level of openness of economy $m$ with regard to economy $p$ at time $t$.

Given that individuals are born workers, the assumption is that they are born already 20 years old. Therefore, the value of $\omega_{m}$ translates into an expected retirement age of 65 years for the G7, following Ferrero, and of 55 for China. For China, this number reflects the legal urban minimum age for 
TABLE 4.1

\begin{tabular}{lcr}
\hline \hline Parameters & Value & Description \\
\hline \hline$\alpha$ & $2 / 3$ & Labor share \\
$\beta$ & 0.993 & Discount factor \\
$\delta$ & 0.1 & Depreciation rate \\
$\sigma$ & 0.5 & Elasticity of intertemporal \\
& substitution \\
$\phi$ & 0.1 & Investment adjustment cost \\
$\bar{\eta}_{m p}$ & 0 & No cost share \\
$\left(1-\omega_{m}\right)^{-1}$ & $45(\mathrm{G} 7)$ and 35 (China) & Average time in labor force \\
\hline
\end{tabular}

retirement averaged across men and women, which has been constant since the $1950 \mathrm{~s}^{1}$.

The paths for the exogenous variables are based on empirical data. They will drive the trajectories of the simulated series. First, the technology growth rates for the U.S. and the G6 are the same as the ones used by Ferrero $(2007)^{2}$. He extracts the Solow residual by first estimating the countries' stock of capital through the method of perpetual inventory, and then applies it in order to extract the total factor productivity (TFP) growth rates. As for China, for the years between 1990 and 2012, I use the series for the TFP growth rate from the Groningen Growth and Development Center (GGDC). For the years before 1990, I estimate the growth rates by a simple linear regression using as a predictor the growth rate of the average productivity, i.e. the growth rate of the real GDP per person employed (adjusted for the purchasing power parity -PPP). ${ }^{3}$. The entire series used to calibrate the Chinese TFP growth can be found in Figure (4.1(a)) alongside the series borrowed from Ferrero. In Section $\mathrm{C}$ of the appendix, I redo the exercise with series of TFP growth consistent with the one used here for China. All three series converge at 2030 to the weighted average of growth rates from 1970 through 2012.

Demographic transition for all three regions is a smoothed trajectory of the rate of growth of the working-age population for the G7 and China. The reason is that demographic transition theoretically determines long run trends in economic data more than short run fluctuations, as is the case of TFP

${ }^{1}$ (Dorfman et al., 2013) states in pp. 19-21 that:

"China's urban retirement ages (60 for men and 50 or 55 for women) have remained unchanged since the 1950s, during which time the proportion of the population represented by the elderly, as well as life expectancy at the time of retirement, have both increased."

${ }^{2}$ The working paper version was chosen to base the calibration because the actual exogenous series the author used can be easily found in the appendix, whereas for the 2010 version, whose calibration is slightly different, the exogenous series are not provided.

${ }^{3}$ The series for the rate of growth of total factor productivity and average productivity exhibit a high correlation from 1990 to 2012 of 0.94 
growth rates. For the United States and the G6 it is given by the growth rate of the population aged 20 through 65 , while for China, whose calibrated average retirement age is 55, it is calculated using the population aged 20 through 55. Figure (4.1(b)) shows the smoothed trajectories alongside the actual data. The United States and G6 start with a growth rate of $1.2 \%$ per year, which is an average of the rates for both regions in 1970. The U.S. roughly maintains this rate until 2005, when it starts to decline, while the G6 faces an early decline in its growth rate. China, on the other hand, is a very interesting case: it starts with a rate of $3 \%$, more than twice the value for the $\mathrm{G} 7$, and then its rate of growth drops dramatically, catching up with and overtaking the United States in the early 2010s. The number of people in working age reaches a peak in 2015 and decline afterwards ${ }^{4}$. For theoretical reasons they all converge to a steady state with no population growth (the simple average of forecasts from 2030 to 2050 is $-0.35 \%$ ). This is because a country cannot exhibit negative population growth rates at a steady state, which would imply an ever-shrinking population, and also because all three regions must converge to the same rate at 2030, otherwise the one growing the faster would eventually take over the entire global economy.

Another demographic variable that plays an important role in the characterization of the demographic transition is life expectancy. Here it is represented by the parameter that reflects the probability of death of a retiree at a certain point in time. The idea is that this parameter should be calibrated according to the average time spent in retirement, that is, according to the life expectancy at retirement. Since this value cannot be found for all years, I will turn this variable endogenous in a sense, and have the actual oldage dependency ratio determine it. The idea here is to pin down the exact population life-cycle dynamics going on behind each region's demographic transition. By using equation (3-3) I can easily insert the data on dependency ratio and retrieve the mortality probability for each period. Thus, when the model is run, the simulated series for the dependency ratio will approximate the data ${ }^{5}$. The series for the dependency ratios and probabilities of death can be found in Figures (4.1(c)) and (4.1(d)), respectively. Notice how substantially the Chinese dependency ratio disconnects from the ratios of the G7 and grows

\footnotetext{
${ }^{4}$ According to Dorfman et al. (2013) the dramatic demographic transition in China and ageing of its population is anticipated to take approximately half the time it took for other countries on average. This is mostly due to the one-child policy introduced in the late 1970s and the increase in longevity. The transition will pose big challenges to the sustainability of the Chinese economy, as with respect to economic growth-China's GPD per capita still puts the country in the middle-income category-as well as with respect to resources to support the elderly

${ }^{5}$ It will not be identical given that from 2030 on the probability of death must be kept constant.
} 
Figure 4.1: Exogenous Variables

(4.1(A)) TFP Growth (\% per year)

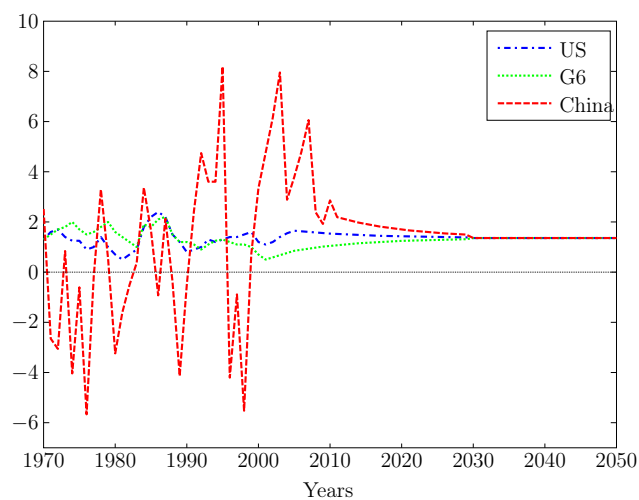

(4.1(c)) Dependency Ratio

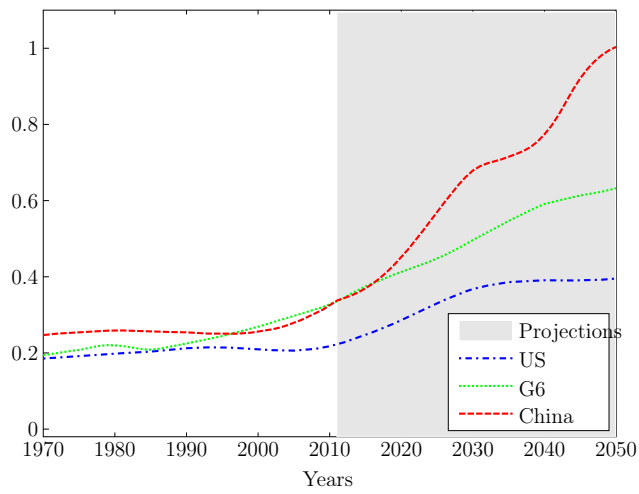

(4.1(E)) Debt-to-GDP Ratio (\% GDP)

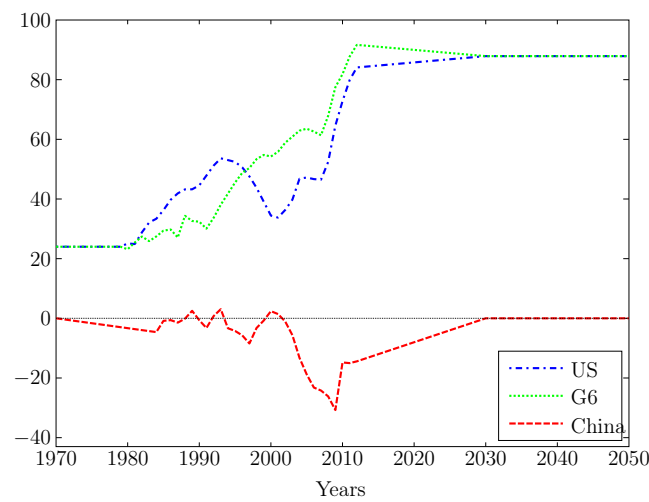

(4.1(в)) Working-Age Pop. Growth (\% per year)

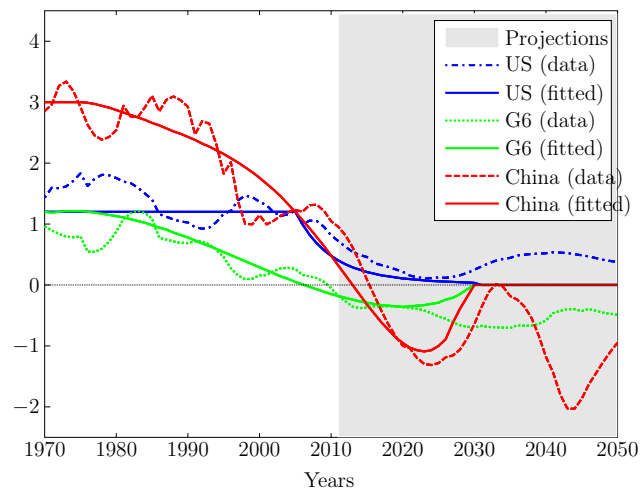

(4.1(D)) Mortality Probability

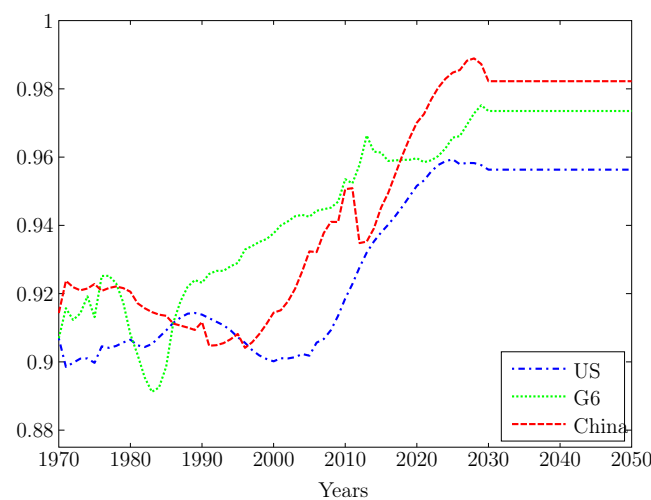

(4.1(F)) Social Security Spending (\% GDP)

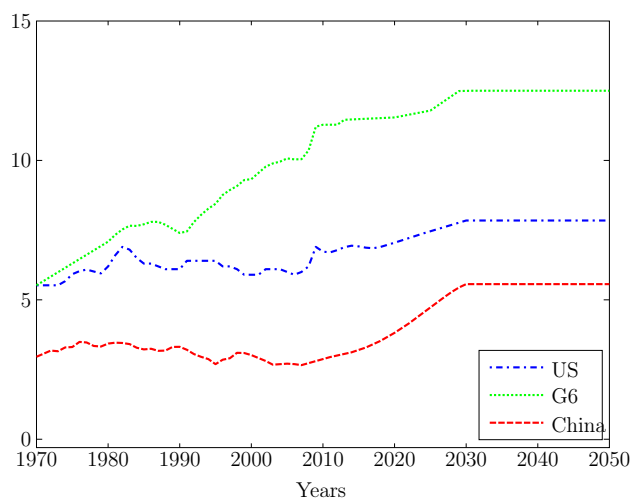


Figure 4.1: Exogenous Variables (continued)

(4.1(A)) Cost of Portfolio

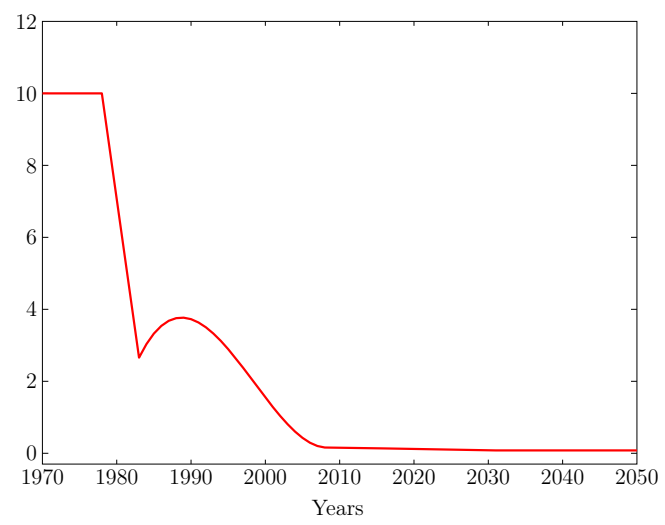

(4.1(B)) Relative Sizes

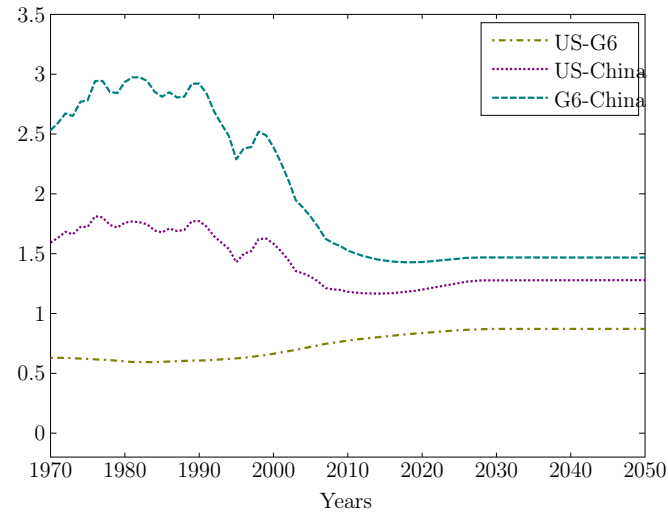

towards a value of one at $2050^{6}$. It is also important to note here that the implied mortality probabilities are at odds with the available data, the focus here was to pin down the evolution of the dependency ratio according to the evidence (see United Nations (2012))

The stance of fiscal policy is given by a time-varying debt-to-GDP ratio. The calibration for the United States and the G6 is based on the ratio of net debt outstanding to GDP. The calibration for China takes the value of the gross outstanding debt and subtracts the amount of foreign reserves excluding gold in order to arrive at an estimate for its net outstanding debt. This calculation renders China a creditor through almost all the simulation. Both initial and final steady states are set to zero, first because in 1970 China was still a socialist economy and second because given the projected path for fiscal and social security variables, debt is definitely expected to increase. At any rate, marginally changing the final level for the Chinese debt-to-GDP ratio will not substantially change the results, as we will see below.

Estimates and forecasts for social security payments for the G7 as a share of GDP are obtained from the OECD for years 1980 through 2050. For the United States, I use the figures from the Congressional Budget Office (CBO) from 1973 up to 1980 and its forecasts, instead of OECD's. The numbers from the U.S. CBO, however, are constantly higher than the ones from the OECD by an average of 1.85 percentage points, probably because they include other expenses as social security. For the sake of coherence, I adjust the numbers from the CBO (including forecasts) to the level of the OECD data for the U.S.

Chinese Social Security: In the case of China, there is only one data

${ }^{6}$ Recall that the comparison is between two distinct sets of people: in the G7, people aged from 20 through 65 and in China from 20 through 55. This projected path depends then on the assumption of a constant minimum retirement age of 55 for the average Chinese. 
point available for the country's social security spending as a share of the GDP: $3 \%$ in 2012. Thus, I estimate its past values and forecasts for future values in the context of the model. The amount a retiree receives each period as pension depends on his or her pre-retirement income and the percentage of this income he or she is entitled to receive during retirement, that is, the replacement rate. However, in this framework, these values would potentially depend on some endogenous variables, which need to be exogenized. Consequently, I make some assumptions: first, that wages and output grow at their steady-state growth rates, i.e. the rate of current technological growth and the rate of current technological growth plus population growth, respectively; and second, that the replacement and coverage rates of the Chinese social security system are constant through time. The latter is a very strong assumption, although it is very conservative with respect to the size of social security system in China, assuming large values when it must have been lower. These values will duly serve the needs of the model.

The calculation goes as follows. First, denote the average pension payment for a retiree in China at period $t$ by $\pi_{C N t}$. In the model every retiree is entitled to receive the same amount as the others, but to understand how pension payments track wages, I will assume that retirees will receive different payments and they will be a constant share $\zeta$ of their last salary. The total amount of pension payments at some period $t$ can then be written as:

$$
E_{C N t}=\pi_{C N t} N_{C N t}^{r}
$$

while the amount for the following period can be written in terms of the current one as:

$$
E_{C N t+1}=\gamma_{C N t, t+1} E_{C N t}+\zeta W_{C N t}^{w}\left(1-\omega_{m}\right) N_{C N t}^{w}
$$

Note that all retirees have the same probability of dying, regardless of how long in retirement they are. Therefore, we can ascertain that the retirees surviving for the following period will receive $\gamma_{C N t, t+1} E_{C N t}$, in aggregate. The just-retired ones will receive a fraction of their final wage, $\zeta W_{C N t}^{w}\left(1-\omega_{m}\right) N_{C N t}^{w}$. Dividing equation (4-2) by (4-1) leads to:

$$
\frac{E_{C N t+1}}{E_{C N t}}=\gamma_{C N t, t+1}+\frac{\zeta W_{C N t}^{w}\left(1-\omega_{C N}\right)}{\pi_{C N t} \psi_{C N t}}
$$

It still remains to define the average pension payment $\pi_{C N t}$. It will be simply given by a weighted average of all payments to all retirees alive at that moment, that is: 


$$
\pi_{C N t}=p_{C N 0 t} \zeta W_{C N 0}^{w}+p_{C N 1 t} \zeta W_{C N 1}^{w}+\ldots+p_{C N t-1, t} \zeta W_{C N t-1}^{w}
$$

where $p_{C N i t}$ is the proportion at $t$ of agents that has been living in retirement for $t-i$ periods. To calculate all these proportions for all periods I had to simulate a population pyramid for retirees using the life-cycle dynamics of the model. I then assumed, as an approximation, that wages grow according to the technological growth (which is true for the steady state). Substituting (4-4) into (4-3) and substituting for wages yield:

$$
\frac{E_{C N t+1}}{E_{C N t}}=\gamma_{C N t, t+1}+\frac{\left(1-\omega_{C N}\right) \prod_{i=1}^{t}\left(1+x_{C N t-i-1, t-i}\right)}{\psi_{C N t} \sum_{j=0}^{t-1} p_{C N j t} \prod_{i=1}^{j}\left(1+x_{C N i-1, i}\right)}
$$

With the equation (4-5) above, and assuming also as an approximation that the GDP grows according to the working-age population growth and technological growth combined, it is possible to retrieve the series for social security spending in China shown in Figure (4.1(f)).

The imperfect capital mobility caught by the variable $\Lambda_{m p t}$ will be modelled as follows: I will assume perfect capital mobility between the United States and the G6 countries, setting $\Lambda_{U S, G 6, t}=\Lambda_{G 6, U S, t}=0.001^{7}$ for all $t$. For the four variables that capture the cost of transacting with China, I will assume them to be identical and follow the path depicted in Figure (4.1(a)). This is due first to equation (3-14), which implies that if any of these variables were set to zero, then interest rates would be equalized in the global market. The second reason for calibrating this variable this way is that it is a reducedform exogenous variable, whose objective here is to measure China's gradual opening to the global economy environment and thus to generate a wedge between the world interest rate, represented by the G7 interest rate, and the domestic Chinese interest rate. Therefore, there will be no conceptual problem in setting all four variables to the same values.

The calibration of these four variables can be divided into two parts. The first part represents the 1970s and the cost is set the highest possible in order to keep China approximately as a closed economy. After 1978, which is the year when economic reforms began to be implemented, the calibration follows the difference between the trends of real interest rates in G7 and China, understood as a proxy for the degree of openness, the higher the difference, the higher the cost parameter. The exact values were calibrated to replicate in the simulation the difference found in the data.

${ }^{7}$ Setting the variable to zero leads to the non-convergence of the simulation. 
The relative sizes of each economy in the model vary according to the trajectories in Figure (4.1(b)), which result not only from the paths for population and technological growth, but also by the initial relative levels of population and technological development.

Section B in the appendix contains the sources and additional details on the data used for the calibration and the analysis of the results below.

\section{2}

\section{Quantitative Results}

Due to potentially ever-growing variables, the non-stationary variables must be written in efficiency units or as shares of the GDP. The computation of steady states and of the transition paths are carried out by a large-scale nonlinear Newton-Raphson method (see Juillard (1996)). At the outset of the simulation, in 1970, al three economies are in a steady-state equilibrium. The United States and the G6 are both identical economies and thus do not engage in any sort of transaction. China, with a considerably different calibration for that year, is set approximately closed by choosing a high value for the cost of holding foreign assets. Then, exogenous variables change unexpectedly in the following year and agents perfectly predict their future trajectories, since they are in a fully deterministic setting. The paths for all exogenous variables drive the transition from the initial steady state up to the final steady state in $2030^{8}$. All exogenous variables reach their steady-state values at 2030, but the simulation is run up until 2050 so that endogenous variables can continuously converge to their final steady states.

The main results can be found in Figure (4.2), where the simulated series are compared to the data. It is worth noting that for the G6 and China the data is on balances versus the world and are not the most suitable series for comparison here. They are used nevertheless due to data unavailability. For the United States, on the other hand, there are data for transactions versus the G6 and China starting from 1999. The data series for the U.S. above thus represents the country's balances versus the world up to 1998 and then versus the G6 and China from that point on.

As far as the long-run trend of each series is concerned, the baseline simulation does a good job in replicating the deterioration of the United States external balances starting in the 1980s. The simulation overestimates the current account deficit by a roughly constant margin from the end of the 1980s on, in contrast, starting from 1990, the model parallels the data series,

${ }^{8}$ The choice of 2030 is distant enough to average out uncertainties in demographic projections. 
Figure 4.2: Simulations (\% GDP)

(4.2(A)) U.S. Current Account

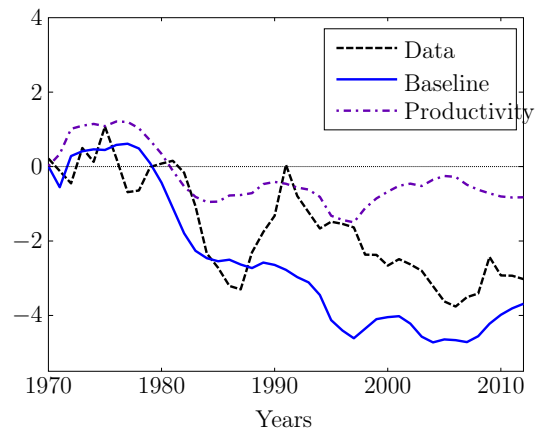

(4.2(B)) G6 Current Account

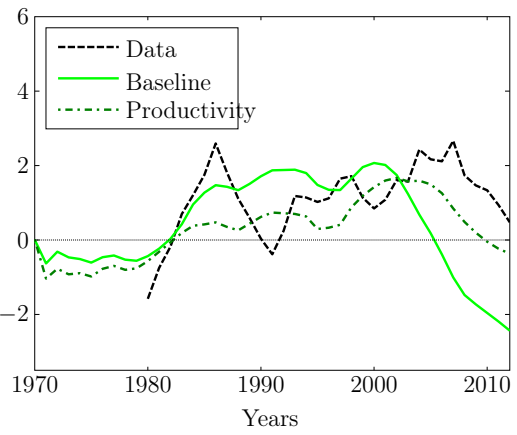

(4.2(C)) Chinese Current Account

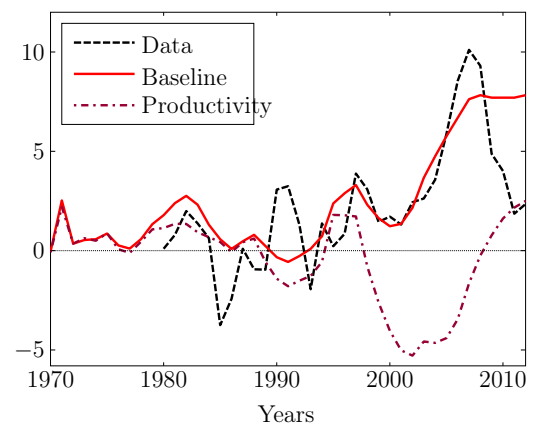

especially during the last decade. The simulation for the G6 balances leaves much to be desired. It can only accomplish the task of replicating the trend in the data up to 2000, when the simulated balances deteriorate, which is at odds with the observed pattern. For China the simulation appears to do a great job in capturing the actual trajectories from 1990 through 2012, which is the period of rapid Chinese growth and transformation into an important economic actor in the world economy. Table (4.2) shows the correlation of each simulation with their respective data series for the entire sample and also for some specific periods.

\subsection{1}

\section{Decomposition}

Productivity: The effect of productivity growth on the imbalances is through the investment channel. Considering two economies exactly identical, except for the rate of technological growth, in a setting with perfect capital mobility, we have that (variables in efficiency units):

$$
i_{m t}-i_{p t}=\left(x_{m t, t+1}-x_{p t, t+1}\right) k_{t}, \quad k_{t} \equiv k_{m t}=k_{p t}
$$

that is, the economy growing the faster will have a higher rate of desired 
TABLE 4.2

\begin{tabular}{lccc}
\hline \hline Correlation & US & G6 & China \\
\hline \hline Current Account & & & \\
Entire sample & $\mathbf{0 . 8 2 7 9}$ & $\mathbf{0 . 0 0 4 8}$ & $\mathbf{0 . 7 0 9 1}$ \\
$1970-1979$ & 0.0103 & - & - \\
$1980-1989$ & 0.8399 & 0.8866 & 0.7888 \\
$1990-1999$ & 0.6919 & -0.4401 & 0.1206 \\
$2000-2012$ & 0.6146 & 0.1091 & 0.5587 \\
\hline
\end{tabular}

investment, leading to a deficit in the external accounts.

In Figure (4.2), there are also the trajectories for the simulation when only productivity rates differ among regions, all other variables (fiscal, demographic, and social security) are held constant at the U.S.-G6 initial levels (for China as well). Note that the role of productivity growth in explaining external imbalances is small, chiefly for the last two decades. Productivity growth can only explain less than one percentage point of the United States current account deficit during the GSG. The gap between this simulation and the data is considerable. It is especially more in the case of China, where due to its rapid technology growth, it turns into a net importer of capital flows (cf. Lucas (1990)).

Hence, there is an important factor that is explaining the recent developments of the Chimerica relationship that resides in the deterministic component of the simulation. The deterministic component is specifically the simulation when only demographic factors ${ }^{9}$ and fiscal factors differ among countries. The decomposition of the deterministic component is carried out by first running the model with only productivity growth held constant relative to the baseline simulation. The trajectories for this simulation are the ones indicated by the continuous black lines in Figure (4.3). Note the importance of this component in explaining the simulated imbalances for the U.S. since 1980, for China since 1990 on and for the G6 only in the last decade.

Fiscal Policy: It becomes clear that the actual driving forces behind the deterministic component are the demographic factors when the debt-to-GDP ratios are held constant across regions. It is important to clarify that this result is not inherent to the model, since, as already noted, Ricardian equivalence is broken here due to the model's life-cycle structure. Fiscal policy, which affects trade and current account deficits through relative consumption and the income account, insofar as expansionary policies lead to external deficits,

\footnotetext{
${ }^{9}$ Social security falls under this category since its path is a function of the demographic transition, not only theoretically, but also by construction, as in China's case
} 
can thus only explain a modest fraction of imbalances Table (4.3) shows two measures for the impact of fiscal policy. The first, depicted in Figure (4.3), refers to the simulation when fiscal policy is removed from the deterministic component and the resulting simulation is compared to the original one. It can be seen that the contribution of fiscal policy in explaining the imbalances barely reaches one fourth of the total for the U.S. and the G6, being even less significant for China: one seventh for the current account balance. The numbers in parentheses represent another measure for the importance of fiscal policy. In this case, the contribution of fiscal policy is measured as the share resultant of the sum of simulations when either demographic factors or fiscal stances alone differ among countries. Its importance in the G6 and China increases, while for the United States it decreases. All in all, however, in both cases the estimates are considerably low.

Social Security: As figure (4.3) shows, the most important factor in determining the global imbalances of the Chimerica relationship is the existence and cross-country differences in social security systems. The last simulation abstracts from this element and lead to completely different results. This simulation only accounts for differences in population growth rate and life expectancy. The numbers in Table (4.3) express the difference between the simulation that takes into consideration both the demographic transitions and the changes in social security spending and the one that does not account for social security, i.e. its value is set to zero for all countries. This difference is given in terms of absolute percentage of the first simulation, which is exactly the same thing done for fiscal policy.

Now, the values for the first two decades are a little uninformative, since the demography simulation is way too close to zero. Thus, it is better to focus on the last two decades, which is also where we see the most dramatic reversal in the imbalances. For the U.S. the average impact of social security in the last two decades seems to be low; however, this is due to the opposing trends of both simulations and to the fact that the impact is measured with respect to the distance to the x-axis. During the last two decades, especially the last one, social security has had the effect of deteriorating the United States external balances. For the last decade social security accounted for an average of $112.38 \%$ of the demography current account.

For the G6, the addition of a social security system led to the counterfactual result that the group has been running deficits since the late 1990s. When it is removed, the series seem to hover around the average level of the data, although this is not the perfect data series for comparison. The counterfactual result seems to be due to the greater insertion of China in the 
Figure 4.3: Decomposition of the Deterministic Component (\% GDP)

(4.3(A)) U.S. Current Account

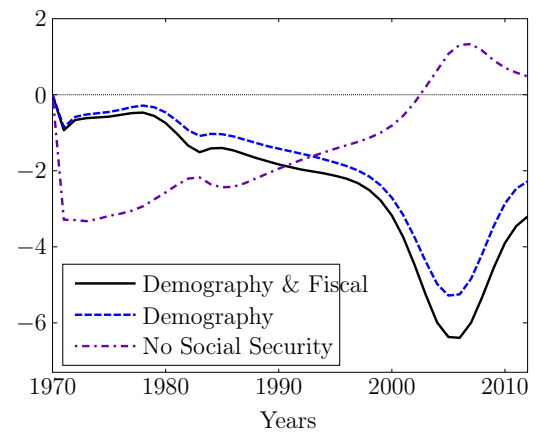

(4.3(c)) Chinese Current Account

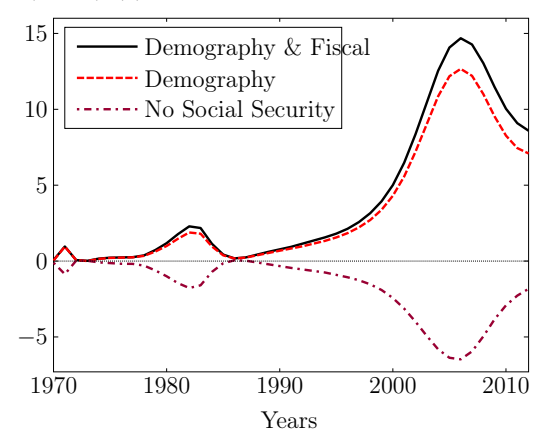

(4.3(в)) G6 Current Account

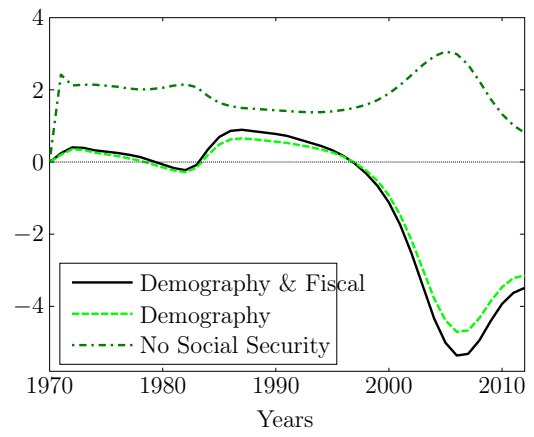

TABle 4.3: Decomposition of the Deterministic Component

\begin{tabular}{lccc}
\hline \hline $\begin{array}{l}\text { Curr. Acc. Balance } \\
\text { (\% change from } \\
\text { prev. simulation) }\end{array}$ & US & G6 & China \\
\hline \hline Fiscal Policy & & & \\
Entire sample & $22.91(12.61)$ & $20.63(24.18)$ & $14.94(23.86)$ \\
$1970-1989$ & $27.18(17.97)$ & $23.19(16.46)$ & $15.28(21.78)$ \\
$1990-2012$ & $19.19(7.94)$ & $18.40(30.92)$ & $14.65(25.68)$ \\
$2000-2012$ & $20.28(12.61)$ & $13.01(24.18)$ & $15.08(23.86)$ \\
\hline Social Security & & & \\
Entire sample & -121.30 & -6.68 & 148.72 \\
1970-1989 & -226.50 & -181.27 & 146.60 \\
1990-2012 & 69.34 & 51.47 & 150.56 \\
$2000-2012$ & 112.38 & 177.88 & 146.57 \\
\hline Pop. Growth & & & \\
Entire sample & 37.95 & 26.75 & 66.40 \\
1970-1989 & 0.17 & 8.66 & 72.55 \\
1990-2012 & 70.81 & 42.49 & 61.32 \\
$2000-2012$ & 114.04 & 46.21 & 49.00 \\
\hline \hline
\end{tabular}

world economy starting at the early 1990s. Despite the G6 having a more slowly growing economy, the differentials in the sizes of the social security systems are of such a magnitude that lead to a drop in savings and make capital flow 
into the region, instead of out of it.

China, in its turn, presents a less developed social security system that takes up a lower share of the country's economy than the G7's. The final result is that, with smaller transfers from workers to retirees, savings will be higher, since the former have a greater propensity to save when compared to retirees. Higher savings are then directed to the rich countries, as opposed to what a pure structural model would predict. For the last decades, the contribution of social security to explain the demography factor is between $145 \%$ and $150 \%$ for the current account balance, which means a reversal of $45 \%$ to $50 \%$.

The takeaway from these results is that a social security system, by decreasing national savings, will lead to a need for importing capital, since desired savings would fall short of desired investments. This is roughly what is simulated for the countries of the G7, the United States in particular. The diminished savings in these countries lead to a higher return on capital which attracts investments from the country with the less developed social security system, which in this case is China. This outcome is in line with the results from Eugeni (2013) and provides quantitative evidence in another life-cycle economy for the same results.

Population Growth and Life Expectancy: When social security is removed, the last two factors accounting for the simulated paths are pure demographic: working-age population growth and life expectancy. Keeping population growth rates constant, I found life expectancy to explain the magnitude of about $62 \%$ (the complement fraction from the ones in the table, since those numbers account for interactions as well) of the current account balance. For the G6 the proportion explained by life expectancy is higher, more than $70 \%$. For China it is the lowest, perhaps because of the fall in population growth rates in China having been so substantial in such a relatively short time.

The mechanism behind the impact of the increase in life expectancy over time on imbalances, is that a higher life expectancy, everything else equal, reduces the marginal propensity to consume as well for retirees as for workers. Take the case of retirees in a steady state with perfect capital mobility, for example. Calling the common world interest rate $R^{W}$, we have:

$$
\varepsilon_{m} \pi_{m}-\varepsilon_{p} \pi_{p}=-\beta^{\sigma}\left(R^{W}\right)^{\sigma-1}\left(\gamma_{m}-\gamma_{p}\right)
$$

which means that a higher life expectancy in country $m$, everything else equal, will lead to a lower marginal propensity to consume and lower consumption, implying higher savings and a surplus in the external accounts. 
Working-age population growth can affect consumption and investment through two conflicting channels ${ }^{10}$. The first one is through the exactly same channel through which differentials in technological growth lead to capital inflows or outflows. If productivity growth is identical across two countries and population growth is allowed to differ, everything else equal, we have a version of equation (4-6). In this case, the economy growing the faster will have a higher rate of investment and experience deficits. The second channel is through changes in the age profile of each country. Given two identical countries, an increase in the population growth rate for the next period in one of them will lead to a younger age profile relative to the other country:

$$
\frac{\psi_{m t+1}}{\psi_{p t+1}}=\frac{1+n_{p t+1}}{1+n_{m t+1}}
$$

The younger country will then present higher savings and a surplus in the external accounts, an opposite effect. By abstracting from population growth in the last exercise, it is possible to gauge which channel is more pronounced. Overall, for the G6 and China, an equalization of population growth rates means higher rates for the former and lower for the latter. Since what we see from Table 4.3 is a decrease in the former's surplus (the surplus of G6's "No Social Security" simulation in Figure (4.3)) and in the latter's deficit, the investment channel is the one that's more pronounced for the G6 and the savings channel the one for China.. For the United States, the equalization does not change the country's rates up until 2005. This explains the low numbers for 1970-1989 and means that the focus must be on the last decade's figures. Numbers higher than $100 \%$ imply an overcorrection and a very strong effect of the investment channel. The investment channel is thus a driving force working in favor of the actual direction of capital flows for the G7 and the savings channel is the driving force working in favor of the actual direction of capital flows for China.

\section{3}

\section{The Decline in Real Interest Rates}

A supply-and-demand framework easily predicts that any increase in the supply of some good, ceteris paribus, will drive the price for these goods down. The Global Saving Glut hypothesis, accordingly, tells that the rise in of global savings drove down the price of these funds: the world real interest rate. It still remains to test how well the model can replicate this pattern and which are the factors that contribute most to this decline. Figure (4.4) depicts the

\footnotetext{
${ }^{10}$ Higgins (1998), examines and finds empirical support for both channels through econometric analysis.
} 
FiguRe 4.4: Real Interest Rates

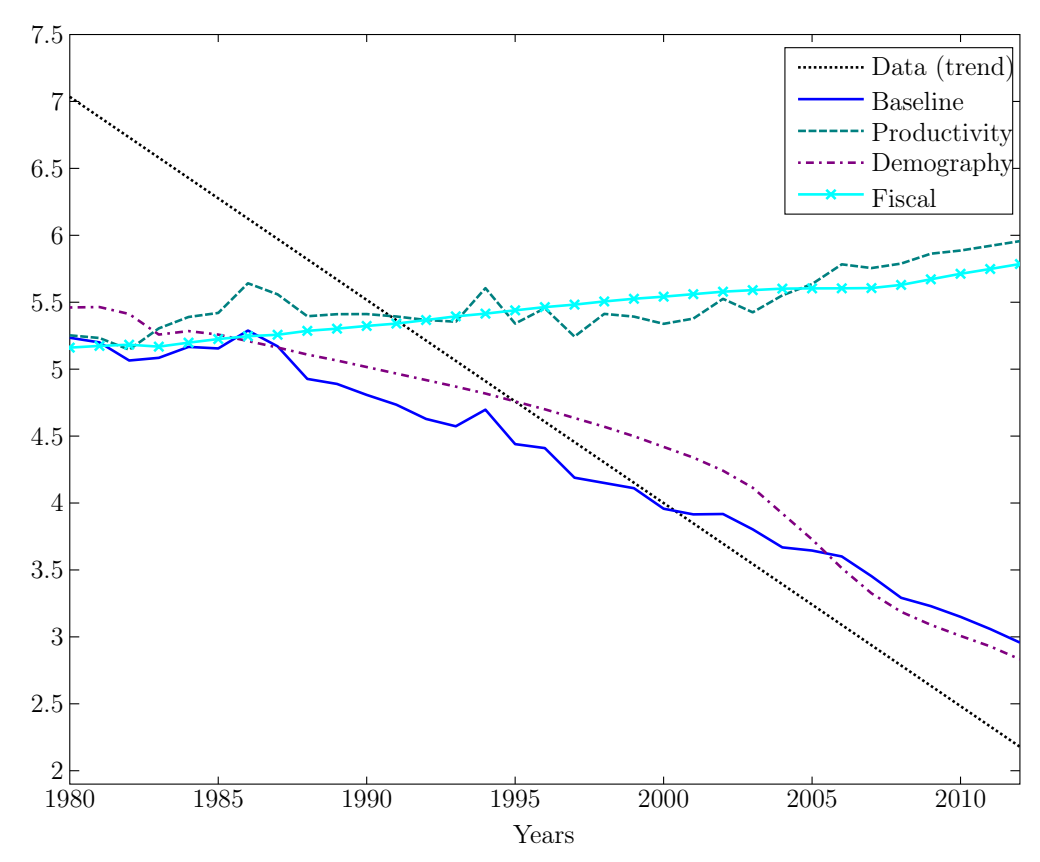

comparison between three simulations for the G7 real interest rates and the linear trend in the data for the group ${ }^{11}$. The baseline simulation replicates well the trend in the data, despite the actual decline being more dramatic than the one in the model economy.

It is very clear from the decomposition that the great driving force behind the decline in real interest rates in the last three decades has been the demographic transition. The previous analysis on the determinants of imbalances and direction of capital flows also applies here, but in absolute terms. Productivity growth influences interest rates in two opposite directions: it spurs consumption and investment at the same time. Since the simulated series has a somewhat positive slope, it means that the consumption channel is a little more pronounced here. Fiscal policy in the G7 has been expansionary throughout most of the last three decades. This explains the increasing rates implied from this factor alone.

One important factor driving interest rates down is life expectancy. As it goes up, agents reduce consumption in order to save for a longer retirement, thus increasing savings and the supply of funds. Working-age population growth may work in the opposite direction by increasing the dependency ratio, but the impact of rising life expectancy more than compensates for this effect. Finally, the impact of a social security system is big. Without it, rates fall by many percentage points, but in parallel with the series the take it into

\footnotetext{
${ }^{11}$ Interest rates in China are regulated and thus the data on China is not representative of the real cost of capital in this country. The data on China is nevertheless used for constructing the series of the cost of capital mobility.
} 
consideration, which means that the decline through time is explained by pure demographic factors alone. 


\section{Conclusion}

Differentials in productivity growth may account for a considerable portion of external imbalances among rich nations; however, a framework that only takes this factor into account poorly explains the most important developments in patterns of capital flows between rich and developing economies. In this regard, the Lucas paradox (Lucas, 1990) imposes an obstacle for structural models, since rapid growing economies, such as emerging markets in general, would clearly attract capital instead of exporting it. This paper addressed this problem by considering differentials in social security systems across countries and their impact on investment and saving rates.

The objective was to analyze and break down the relationship between rich economies and the most important and dynamic emerging economy of the last decades: China. The symbiotic (or not) relationship between the United States and China, which was dubbed Chimerica, is believed to have set the stage for the development of the last financial crisis and has not yet subsided.

The main result is that social security system differentials promote a reversal of capital flows when compared to a global economy with no social security systems. Therefore, these differentials play the most prominent role in determining the magnitude of imbalances, at least for the last two decades, which is when imbalances become way more pronounced. Productivity differentials may explain well the transactions inside the G7, but when China is introduced, they are not able to account for the actual pattern of imbalances and produce counterfactual results.

Fiscal policy has a limited role in explaining the imbalances, they barely reach one quarter of the total effect of the deterministic component. Purely demographic factors, the increase in life expectancy and the declining population growth rates have an important role in determining the trajectory of external imbalances.

As the last test for the model's explanatory capacity, the sustained fall in the world interest rates since the 1980s can be very well replicated. The decomposition of this downward trend shows that it is mostly a consequence of the demographic transition all countries are going through lately. A longer lifespan, given a constant age for retirement, means a longer unproductive period in retirement and thus lead workers and retirees to consume less and save more. The widespread increase in savings, the Global Saving Glut, as it was called, drives down the world real interest rate. 
The work of Ferrero (2010) achieves a better fitting for the baseline simulation, especially with regard to the U.S. trade balance up to the year 1990. In contrast, his model finds a larger role for productivity differences in accounting for global imbalances among rich nations and a small, but not negligible and permanent, role for demographic factors. The model presented here, on the other hand, finds productivity differentials to explain only one percent of the GSG period. Ferrero finds the deterministic component to be of lower importance and fiscal factors to explain an average of $35.2 \%$ of this component, while here they are responsible for $22.9 \%$. Within the pure demographic factors, he finds differences in life expectancy to account for roughly a half of these factors, while here the estimate is a little bit higher, $62 \%$, but in line with his, the rest is then explained by working-age population growth. He also finds demography to be the main driver of the secular fall in real interest rates.

This paper also provided a new and simple way to connect two extreme benchmarks: the closed economy and the open economy with perfect capital mobility. I introduce a reduced-form parameter that controls the degree of openness of each economy, and may thus provide a new standard with which to study capital flows and external account imbalances.

Despite the satisfactory results in general, the model has abstracted from some important features a emerging economy such as China may present. First, the model lumps skilled and unskilled labor into only one category, thus abstracting from the composition of each country's labor force. When taking into account that emerging economies have a greater share of unskilled workers in their labor force, the capital-labor ratio in these economies go up, implying lower returns on capital and therefore another factor that can probably account for the observed pattern of capital flows. Second, the model abstracts from any consideration of sovereign risk, which may turn out to be of great importance for some unstable emerging economies. Third, there are many more institutional differences between rich and emerging economies that can be considered. Caballero, Fahri and Gourinchas (2008) and Mendoza, Quadrini and Rios-Rull (2009) consider differentials in financial market developments as a cause of increased savings in emerging economies and thus also present an important characteristic of developing economies that very likely affects the patterns of capital flows. 


\section{Bibliography}

ATTANASIO, O., S. K.; VIOLANTE, G. Quantifying the effects of the demographic transition in developing economies. Advances in Macroeconomics. The B.E. Journals in Macroeconomics., v. 6, p. Article 2, 2006.

ATTANASIO, O., S. K.; VIOLANTE, G. Global demographic trends and social security reform. Journal of Monetary Economics, v. 54, p. 144-98, 2007.

BERNANKE, B. The global saving glut and the u.s. current account deficit. In: Sandridge Lecture. Virginia Association of Economics. Richmond, VA, 2005.

BERNANKE, B.; BERTAUT, C.; DEMARCO, L. P.; KAMIN, S. International capital flows and the returns to safe assets in the united states, 2003-2007. International Finance Discussion Papers, , n. 1014, 2011.

BLANCHARD, O. Debt, deficits and finite horizons. Journal of Political Economy, v. 93, p. 223-247, 1985.

BROOKS, R. Population aging and global capital flows in a parallel universe. IMF Staff Papers, v. 50(2), p. 3-13, 2003.

CABALLERO, R., E. F.; GOURINCHAS, E. An equilibrium model of "global imbalances" and low interest rates. American Economic Review, v. 98, p. 358393, 2008.

CHANG, C., Z. L.; SPIEGEL, M. Capital controls and optimal chinese monetary policy. Federal Reserve Bank of San Francisco Working Paper Series, 2013.

DIAMOND, P. National debt in a neoclassical growth model. American Economic Review, v. 55(5), p. 1126-1150, 1965.

DORFMAN, M.; HOLZMANN, R.; O'KEEFE, P.; WANG, D.; SIN, Y.; HINZ, R. China's pension system: A vision. doi: 10.1596/978-0-8213-9540-0: Washington, DC: World Bank, 2013.

EPSTEIN, L.; ZIN, S. Substitution, risk aversion, and the temporal behavior of consumption and asset returns: A theoretical framework. Econometrica, 1989.

EUGENI, S. An olg model of global imbalances. Discussion Papers in Economics, v. 13/05, 2013. 
FARMER, R. Rince preferences. Quarterly Journal of Economics, v. 105, p. 43-60, 1990.

FEHR, H., S. J.; KOTLIKOFF, L. Will china eat out lunch or take us out to dinner? simulating the transition paths of the u.s., eu, japan and china. NBER Working Paper, , n. 11668, 2005.

FELDSTEIN, M. Social security, induced retirement, and aggregate capital accumulation. The Journal of Political Economy, v. 82, p. 905-926, 1974.

FELDSTEIN, M.; LIEBMAN, J. Social security. In: AUERBACH, A.; FELDSTEIN, M. (Eds.) Handbook of Public Economics. North-Holland, 2002. v. 4, Cap. 32 , p. $2246-2324$.

FERGUSON, N. Not two countries, but one: Chimerica. The Telegraph, 04 March 2007.

FEROLI, M. Capital flows among the g-7 nations: A demographic perspective. Finance and Economic Discussion Series, v. 2003-54, 2003.

FERRERO, A. Journal of monetary economics. The Long-Run Determinants of the U.S. External Imbalances, p. 478-490, 2007.

FERRERO, A. A structural decomposition of the u.s. trade balance: Productivity, demographics and fiscal policy. Federal Reserve Bank of New York Staff Reports, v. $295,2010$.

GERTLER, M. Government debt and social security in a life-cycle economy. Carnegie- Rochester Conference Series on Public Policy, v. 50, p. 61-110, 1999.

HENRIKSEN, E. A demographic explanation of u.s. and japanese current account behavior. Working Paper, 2002.

HIGGINS, M. Demography, national savings and international capital flows. International Economic Review, v. 39, p. 343-369, 1998.

JUILLARD, M. Dynare: A program for the resolution and simulation of dynamic models with forward variables through the use of relaxation algorithm. Couverture Orange, , n. 9602, 1996.

LUCAS, R. Why doesn't capital flow from rich to poor countries? American Economic Review, v. 80, p. 92-96, 1990.

MENDOZA, E., V. Q.; RIOS-RULL, V. Financial integration, financial development and global imbalances. Journal of Political Economy, v. 117, p. 371-416, 2009. 
SAMWICK, A. Is pension reform conducive to higher savings? The Review of Economics and Statistics, v. 82 (2), p. 264-272, 2000.

UNITED NATIONS, D. O. E.; SOCIAL AFFAIRS, P. D. World population prospects: The 2012 revision, dvd edition. ., 2012.

YAARI, M. Uncertain lifetime, life insurance, and the theory of the consumer. Review of Economic Studies, v. 32, p. 137-150, 1965. 


\section{A}

\section{Analytical Appendix}

This first part describes the solutions for agents and firms' maximization problem and also characterizes the steady state.

\section{A.1}

\section{Solution for agents' problems}

\section{A.1.1}

\section{Retirees}

The retirees' problem to maximize (3-6) with respect to (3-5). By substituting the constraint into the objective function, the problem becomes an unconstrained maximization problem (cohort superscripts are dropped in order not to clutter notation, bear in mind though that variables with no superscripts actually refer to aggregates):

$$
\begin{aligned}
V_{m t}^{r}=\max _{\left\{A_{m \ell t}^{r}\right\}_{m \in \Theta}} & {\left[\left(\frac{1}{\gamma_{m t-1, t}} \sum_{\ell \in \Theta} R_{\ell t-1} A_{m \ell t-1}^{r}+E_{m t}^{r}-\sum_{\ell \in \Theta} A_{m \ell t}^{r} \times\right.\right.} \\
& \left.\left.\times\left(1+\sum_{\ell \neq m} \frac{\Lambda_{m \ell t}}{2}\left(\eta_{m \ell t}^{r}-\bar{\eta}_{n m}\right)^{2}\right)\right)^{\rho}+\gamma_{m t, t+1} \beta\left(V_{m t+1}^{r}\right)^{\rho}\right]^{\frac{1}{\rho}}
\end{aligned}
$$

The first-order conditions of the problem above with respect to each type of assets yield:

$A_{m m t}^{r}$

$$
\begin{array}{r}
\left(\left(1+\sum_{\ell \neq m} \frac{\Lambda_{m \ell t}}{2}\left(\eta_{m \ell t}^{r}-\bar{\eta}_{m \ell}\right)^{2}\right)-\sum_{\ell \neq m} \Lambda_{m \ell t}\left(\eta_{m \ell t}^{r}-\bar{\eta}_{m \ell}\right) \eta_{m \ell t}^{r}\right)\left(C_{m t}^{r}\right)^{\rho-1}= \\
=\beta \gamma_{m t, t+1}\left(V_{m t+1}^{r}\right)^{\rho-1} \frac{\partial V_{m t, t+1}^{r}}{A_{m m t}^{r}}
\end{array}
$$




$$
\begin{aligned}
& A_{m p t}^{r}, \forall p \neq m: \\
& \quad\left(\left(1+\sum_{\ell \neq m} \frac{\Lambda_{m \ell t}}{2}\left(\eta_{m \ell t}^{r}-\bar{\eta}_{m \ell}\right)^{2}\right)-\sum_{\ell \neq m} \Lambda_{m \ell t}\left(\eta_{m \ell t}^{r}-\bar{\eta}_{m \ell}\right) \eta_{m \ell t}^{r}+\Lambda_{m p t} \times\right. \\
& \left.\quad \times\left(\eta_{m p t}^{r}-\bar{\eta}_{m p}\right)\left(1-\eta_{m p t}^{r}\right)\right)\left(C_{m t}^{r}\right)^{\rho-1}=\beta \gamma_{m t, t+1}\left(V_{m t+1}^{r}\right)^{\rho-1} \frac{\partial V_{m t, t+1}^{r}}{A_{m p t}^{r}}
\end{aligned}
$$

By the Envelope Theorem it is possible to find the partial derivatives above:

$$
\frac{\partial V_{m t, t+1}^{r}}{A_{m p t}^{r}}=\left(V_{m t+1}^{r}\right)^{1-\rho}\left(C_{m t+1}^{r}\right)^{\rho-1} \frac{1}{\gamma_{m t, t+1}} R_{p t}, \forall p \in \Theta
$$

Substituting (A-4) into (A-2) leads to:

$$
\begin{array}{r}
\left(\left(1+\sum_{\ell \neq m} \frac{\Lambda_{m \ell t}}{2}\left(\eta_{m \ell t}^{r}-\bar{\eta}_{m \ell}\right)^{2}\right)-\sum_{\ell \neq m} \Lambda_{m \ell t}\left(\eta_{m \ell t}^{r}-\bar{\eta}_{m \ell}\right) \eta_{m \ell t}^{r}\right)\left(C_{m t}^{r}\right)^{\rho-1}= \\
=\beta R_{m t}\left(C_{m t+1}^{r}\right)^{\rho-1}
\end{array}
$$

while substituting it into (A-3) results in:

$$
\begin{aligned}
& \left(\left(1+\sum_{\ell \neq m} \frac{\Lambda_{m \ell t}}{2}\left(\eta_{m \ell t}^{r}-\bar{\eta}_{m \ell}\right)^{2}\right)-\sum_{\ell \neq m} \Lambda_{m \ell t}\left(\eta_{m \ell t}^{r}-\bar{\eta}_{m \ell}\right) \eta_{m \ell t}^{r}+\right. \\
& \left.\quad+\Lambda_{m p t}\left(\eta_{m p t}^{r}-\bar{\eta}_{m p}\right)\left(1-\eta_{m p t}^{r}\right)\right)\left(C_{m t}^{r}\right)^{\rho-1}=\beta R_{p t}\left(C_{m t+1}^{r}\right)^{\rho-1}
\end{aligned}
$$

Now, dividing (A-5) by (A-6) and rearranging lead to equation (3-8):

$$
\left(1+\sum_{\ell \neq m} \frac{\Lambda_{m \ell t}}{2}\left(\eta_{m \ell t}^{r}-\bar{\eta}_{m \ell}\right)^{2}\right)\left(R_{p t}-R_{m t}\right)=\Lambda_{m p t}\left(\eta_{m p t}^{r}-\bar{\eta}_{m p}\right) R_{m t}
$$

If we multiply equation (A-5) by $\eta_{m m t}^{r}$ and equation (A-6) by $\sum_{\ell \neq m} \eta_{m \ell t} \eta_{m \ell t}^{r}$ and sum them up, we will find the Euler equation for the optimal path of consumption of retirees:

$$
C_{m t+1}^{r}=\left(\frac{\beta \sum_{\ell \in \Theta} \eta_{m \ell t}^{r} R_{\ell t}}{1+\sum_{\ell \neq m} \frac{\Lambda_{m \ell t}}{2}\left(\eta_{m \ell t}^{r}-\bar{\eta}_{m \ell}\right)^{2}}\right)^{\sigma} C_{m t}^{r}
$$

In order to find the difference equation for the marginal propensity to consume out of wealth (mpcw) for retirees, it is necessary to substitute the 
retiree's budget constraint (3-5) into the guess for the policy function (3-9). It still remains, however, to define the sum of discounted future pension payments, $S_{m t}^{r}$. The discount rate will be a weighted average of all interest rates adjusted by the portfolio cost and the probability of surviving, which is the effective interest rate a retiree in country $m$ faces. It can then be defined as follows:

$$
\begin{aligned}
& S_{m t}^{r}=\sum_{v=0}^{\infty} \frac{E_{m t+v}^{r}}{\prod_{z=1}^{v} \frac{1}{\gamma_{m, t+z-1, t+z}} \frac{\sum_{\ell \in \Theta} \eta_{m \ell t}^{r} R_{\ell t}}{1+\sum_{\ell \neq m} \frac{\Lambda_{m \ell t}}{2}\left(\eta_{m \ell t}^{r}-\bar{\eta}_{m \ell}\right)^{2}}}= \\
& =E_{m t}^{r}+\frac{S_{m t+1}^{r}}{\frac{1}{\gamma_{m t, t+1}} \frac{\sum_{\ell \in \Theta} \eta_{m \ell \ell}^{r} R_{\ell t}}{1+\sum_{\ell \neq m} \frac{\Lambda_{m \ell t}}{2}\left(\eta_{m \ell t}^{r}-\bar{\eta}_{m \ell}\right)^{2}}}
\end{aligned}
$$

Substituting and rearranging lead to:

$$
\begin{aligned}
\frac{1-\varepsilon_{m t} \pi_{m t}}{\varepsilon_{m t} \pi_{m t}} C_{m t}^{r}=\left(1+\sum_{\ell \neq m} \frac{\Lambda_{m \ell t}}{2}\left(\eta_{m \ell t}^{r}-\right.\right. & \left.\left.\bar{\eta}_{m \ell}\right)^{2}\right) \sum_{\ell \in \Theta} A_{m \ell t}^{r}+ \\
& +\gamma_{m t, t+1} \frac{S_{m t+1}^{r}}{\frac{\sum_{\ell \in \Theta} \eta_{m \ell t}^{r} R_{m t}}{1+\sum_{\ell \neq m} \frac{\Lambda_{m \ell t}}{2}\left(\eta_{m \ell t}^{r} \bar{\eta}_{m \ell}\right)^{2}}}
\end{aligned}
$$

Now, take the Euler equation for consumption (A-7) and substitute it for $C_{m t}^{r}$ in order to obtain:

$$
\begin{aligned}
& \frac{1-\varepsilon_{m t} \pi_{m t}}{\varepsilon_{m t} \pi_{m t}} C_{m t+1}^{r}\left(\frac{\beta \sum_{\ell \in \Theta} \eta_{m \ell t}^{r} R_{\ell t}}{1+\sum_{\ell \neq m} \frac{\Lambda_{m \ell t}}{2}\left(\eta_{m \ell t}^{r}-\bar{\eta}_{m \ell}^{r}\right)^{2}}\right)^{-\sigma}= \\
& =\left(1+\sum_{\ell \neq m} \frac{\Lambda_{m \ell t}}{2}\left(\eta_{m \ell t}^{r}-\bar{\eta}_{m \ell}\right)^{2}\right) \sum_{\ell \in \Theta} A_{m \ell t}^{r}+\gamma_{m t, t+1} \frac{S_{m t+1}^{r}}{\frac{\sum_{\ell \in \Theta} \eta_{m \ell t}^{r} R_{m t}}{1+\sum_{\ell \neq m} \frac{\Lambda_{m \ell t}}{2}\left(\eta_{m \ell t}^{r} \bar{\eta}_{m \ell}\right)^{2}}}
\end{aligned}
$$

The next step is to substitute the guess function (3-9) at $t+1$ for $C_{m t+1}^{r}$ in order to obtain equation (3-10): 


$$
\begin{aligned}
& \frac{1-\varepsilon_{m t} \pi_{m t}}{\varepsilon_{m t} \pi_{m t}} \varepsilon_{m t+1} \pi_{m t+1}\left(\frac{1}{\gamma_{m t, t+1}} \sum_{\ell \in \Theta} R_{\ell t} A_{m \ell t}^{r}+S_{m t+1}^{r}\right) \times \\
& \times\left(\frac{\beta \sum_{\ell \in \Theta} \eta_{m \ell t}^{r} R_{\ell t}}{1+\sum_{\ell \neq m} \frac{\Lambda_{m \ell t}}{2}\left(\eta_{m \ell t}^{r}-\bar{\eta}_{m \ell}^{r}\right)^{2}}\right)^{-\sigma}=\left(1+\sum_{\ell \neq m} \frac{\Lambda_{m \ell t}}{2}\left(\eta_{m \ell t}^{r}-\bar{\eta}_{m \ell}\right)^{2}\right) \times \\
& \times \sum_{\ell \in \Theta} A_{m \ell t}^{r}+\gamma_{m t, t+1} \frac{S_{m t+1}^{r}}{\frac{\sum_{\ell \in \Theta} \eta_{m \ell t}^{r} R_{m t}}{1+\sum_{\ell \neq m} \frac{\Lambda_{m \ell t}}{2}\left(\eta_{m \ell t}^{r} \bar{\eta}_{m \ell}\right)^{2}}}
\end{aligned}
$$

Finally, the last step is to divide the whole equation by $\sum_{\ell \in \Theta} A_{m \ell t}^{r}$ and use the definition of $\eta_{m \ell t}$, gather identical terms so as to simplify the expression, rearrange and cancel the identical multiplicative terms with $S_{m t+1}^{r}$ from both sides of the equation in order to arrive at equation (3-10):

$$
\varepsilon_{m t} \pi_{m t}=1-\gamma_{m t, t+1} \beta^{\sigma}\left(\frac{\sum_{m \in \Theta} \eta_{m \ell t}^{r} R_{m t}}{1+\sum_{\ell \neq m} \frac{\Lambda_{m \ell t}}{2}\left(\eta_{m \ell t}^{r}-\bar{\eta}_{m \ell}\right)^{2}}\right)^{\sigma-1} \frac{\varepsilon_{m t} \pi_{m t}}{\varepsilon_{m t+1} \pi_{m t+1}}
$$

It remains to find the functional form for the value function. We will guess and verify that it is a share of the current consumption:

$$
V_{m t}^{r}=\Delta_{m t}^{r} C_{m t}^{r}
$$

Substitute then the guess above into the value function and substitute the Euler equation (A-7) for $C_{m t+1}^{r}$ in order to obtain:

$$
\begin{aligned}
\Delta_{m t}^{r} C_{m t}^{r}=\left[\left(C_{m t}^{r}\right)^{\rho}\right. & +\beta \gamma_{m t, t+1}\left(\Delta_{m t, t+1}^{r}\right)^{\rho} \times \\
& \left.\times\left(\frac{\beta \sum_{\ell \in \Theta} \eta_{m \ell t}^{r} R_{\ell t}}{1+\sum_{\ell \neq m} \frac{\Lambda_{m \ell t}}{2}\left(\eta_{m \ell t}^{r}-\bar{\eta}_{m \ell}\right)^{2}}\right)^{\frac{\rho}{1-\rho}}\left(C_{m t}^{r}\right)^{\rho}\right]^{\frac{1}{\rho}}
\end{aligned}
$$

Simplifying (A-13) by crossing out $C_{m t}^{r}$ and rearranging lead to:

$$
\frac{1}{\left(\Delta_{m t}^{r}\right)^{\rho}}=1-\gamma_{m t, t+1} \beta^{\sigma}\left(\frac{\sum_{\ell \in \Theta} \eta_{m \ell t}^{r} R_{\ell t}}{1+\sum_{\ell \neq m} \frac{\Lambda_{m \ell t}}{2}\left(\eta_{m \ell t}^{r}-\bar{\eta}_{m \ell}\right)^{2}}\right)^{\sigma-1} \frac{\left(\Delta_{m t+1}^{r}\right)^{\rho}}{\left(\Delta_{m t}^{r}\right)^{\rho}}
$$

Note that by comparing (A-14) with the difference equation for the mpcw, (3-10), we can find the value of $\Delta_{m t}^{r}$ in terms of the mpcw:

$$
\Delta_{m t}^{r}=\frac{1}{\left(\varepsilon_{m t} \pi_{m t}\right)^{\frac{1}{\rho}}}
$$


This ends the solution for the retiree's problem, the following section deals with the worker's.

\section{A.1.2}

\section{Workers}

The worker's problem, in turn, is to maximize the objective function (3-12) with respect to (3-11). Again, substituting the constraint into the objective function allows us to solve the problem as an unconstrained maximization problem:

$$
\begin{aligned}
& V_{m t}^{w j}=\max _{\left\{A_{m \ell t}^{w j}\right\}_{m \in \Theta}}\left[\left(\sum_{\ell \in \Theta} R_{\ell t-1} A_{m \ell t-1}^{w j}+W_{m t}^{w j}-T_{m t}^{w j}-(1+\right.\right. \\
& \left.\left.\left.+\sum_{\ell \neq m} \frac{\Lambda_{m \ell t}}{2}\left(\eta_{m \ell t}^{w j}-\bar{\eta}_{n m}\right)^{2}\right) \sum_{\ell \in \Theta} A_{m \ell t}^{w j}\right)^{\rho}+\beta\left(\omega_{m} V_{m t+1}^{w j}+\left(1-\omega_{m}\right) V_{m t+1}^{r j t+1}\right)^{\rho}\right]^{\frac{1}{\rho}}
\end{aligned}
$$

The first-order conditions with respect to each type of asset result in (despite the abuse of notation, superscripts are dropped henceforth):

$A_{m m t}^{r}$ :

$$
\begin{aligned}
& \left(\left(1+\sum_{\ell \neq m} \frac{\Lambda_{m \ell t}}{2}\left(\eta_{m \ell t}^{w}-\bar{\eta}_{m \ell}\right)^{2}\right)-\sum_{\ell \neq m} \Lambda_{m \ell t}\left(\eta_{m \ell t}^{w}-\bar{\eta}_{m \ell}\right) \eta_{m \ell t}^{w}\right)\left(C_{m t}^{w}\right)^{\rho-1}= \\
& =\beta\left(\omega_{m} V_{m t+1}^{w}+\left(1-\omega_{m}\right) V_{m t+1}^{r}\right)^{\rho-1}\left(\omega_{m} \frac{\partial V_{m t, t+1}^{w}}{A_{m m t}^{w}}+\left(1-\omega_{m}\right) \frac{\partial V_{m t, t+1}^{r}}{A_{m m t}^{r}}\right)
\end{aligned}
$$

$A_{m p t}^{r}, \forall p \neq m:$

$$
\begin{aligned}
&\left(\left(1+\sum_{\ell \neq m} \frac{\Lambda_{m \ell t}}{2}\left(\eta_{m \ell t}^{w}-\bar{\eta}_{m \ell}\right)^{2}\right)\right.-\sum_{\ell \neq m} \Lambda_{m \ell t}\left(\eta_{m \ell t}^{w}-\bar{\eta}_{m \ell}\right) \eta_{m \ell t}^{w}+ \\
&\left.+\Lambda_{m p t}\left(\eta_{m p t}^{w}-\bar{\eta}_{m p}\right)\left(1-\eta_{m p t}^{w}\right)\right)\left(C_{m t}^{w}\right)^{\rho-1}=\beta\left(\omega_{m} V_{m t+1}^{w}+\left(1-\omega_{m}\right) V_{m t+1}^{r}\right)^{\rho-1} \times \\
& \times\left(\omega_{m} \frac{\partial V_{m t, t+1}^{w}}{A_{m m t}^{w}}+\left(1-\omega_{m}\right) \frac{\partial V_{m t, t+1}^{r}}{A_{m m t}^{r}}\right)
\end{aligned}
$$

Again, the Envelope Theorem gives the expressions for the partial derivatives above: 


$$
\frac{\partial V_{m t+1}^{w}}{\partial A_{m p t}^{w}}=\left(V_{m t+1}^{w}\right)^{1-\rho}\left(C_{m t+1}^{w}\right) R_{p t}
$$

In order to continue with the derivation, it is necessary that we already guess the functional form of the worker's value function:

$$
V_{m t}^{w}=\Delta_{m t}^{w} C_{m t}^{w}, \text { with } \Delta_{m t}^{w}=\pi_{m t}
$$

By substituting equation (A-19) and the guess (A-20) first into equation (A-17) we get:

$$
\begin{gathered}
\left(\left(1+\sum_{\ell \neq m} \frac{\Lambda_{m \ell t}}{2}\left(\eta_{m \ell t}^{w}-\bar{\eta}_{m \ell}\right)^{2}\right)-\sum_{\ell \neq m} \Lambda_{m \ell t}\left(\eta_{m \ell t}^{w}-\bar{\eta}_{m \ell}\right) \eta_{m \ell t}^{w}\right)\left(C_{m t}^{w}\right)^{\rho-1}= \\
=\beta\left(\omega_{m} \Delta_{m t+1}^{w} C_{m t+1}^{w}+\left(1-\omega_{m}\right) \Delta_{m t+1}^{r} C_{m t+1}^{r}\right)^{\rho-1} \times \\
\times\left(\omega_{m}\left(\Delta_{m t+1}^{w}\right)^{1-\rho}+\left(1-\omega_{m}\right)\left(\Delta_{m t+1}^{r}\right)^{1-\rho}\right)
\end{gathered}
$$

Now, multiplying the right-hand side of $(\mathrm{A}-21)$ by $\left(\Delta_{m t+1}^{w} / \Delta_{m t+1}^{w}\right)^{1-\rho}$ and rearranging yield:

$$
\begin{aligned}
& \left(\omega_{m} C_{m t+1}^{w}+\left(1-\omega_{m}\right) \frac{\Delta_{m t+1}^{r}}{\Delta_{m t+1}^{w}} C_{m t+1}^{r}\right)^{1-\rho}= \\
& =\left(\frac{\beta\left(\omega_{m}+\left(1-\omega_{m}\right) \frac{\left(\Delta_{m t+1}^{r}\right)^{1-\rho}}{\left(\Delta_{m t+1}^{w}\right)^{1-\rho}}\right) R_{m t}}{\left(1+\sum_{\ell \neq m} \frac{\Lambda_{m \ell t}}{2}\left(\eta_{m \ell t}^{w}-\bar{\eta}_{m \ell}\right)^{2}\right)-\sum_{\ell \neq m} \Lambda_{m \ell t}\left(\eta_{m \ell t}^{w}-\bar{\eta}_{m \ell}\right) \eta_{m \ell t}^{w}}\right)\left(C_{m t}^{r}\right)^{1-\rho}
\end{aligned}
$$

Recall that we found in solving the problem of the retiree that $\Delta_{m t}^{r}=$ $1 /\left(\varepsilon_{m t} \pi_{m t}\right)^{1 / \rho}$ and we also guessed the value of $\Delta_{m t}^{w}$ to be $1 /\left(\pi_{m t}\right)^{1 / \rho}$. Substituting these two expressions for both $\Delta_{m t}^{r}$ and $\Delta_{m t}^{w}$ in (A-22) gives:

$$
\begin{aligned}
& \left(\omega_{m} C_{m t+1}^{w}+\left(1-\omega_{m}\right) \varepsilon_{m t+1}^{\frac{\sigma}{1-\sigma}} C_{m t+1}^{r}\right)^{1-\rho}= \\
& =\left(\frac{\beta\left(\omega_{m}+\left(1-\omega_{m}\right) \varepsilon_{m t+1}^{\frac{1}{1-\sigma}}\right) R_{m t}}{\left(1+\sum_{\ell \neq m} \frac{\Lambda_{m \ell t}}{2}\left(\eta_{m \ell t}^{w}-\bar{\eta}_{m \ell}\right)^{2}\right)-\sum_{\ell \neq m} \Lambda_{m \ell t}\left(\eta_{m \ell t}^{w}-\bar{\eta}_{m \ell}\right) \eta_{m \ell t}^{w}}\right)\left(C_{m t}^{r}\right)^{1-\rho}
\end{aligned}
$$


The next step is to substitute the equation of the Envelope Theorem, (A-19), and the guess for the value function, (A-20), into (A-18). Following basically the same steps taken to find equation (A-23), we get, for any $p \neq m$ :

$$
\begin{gathered}
\left(\omega_{m} C_{m t+1}^{w}+\left(1-\omega_{m}\right) \varepsilon_{m t+1}^{\frac{\sigma}{1-\sigma}} C_{m t+1}^{r}\right)^{1-\rho}= \\
\left(\frac{\beta\left(\omega_{m}+\left(1-\omega_{m}\right) \varepsilon_{m t+1}^{\frac{1}{1-\sigma}}\right) R_{p t}}{\left(1+\sum_{\ell \neq m} \frac{\Lambda_{m \ell t}}{2}\left(\eta_{m \ell t}^{w}-\bar{\eta}_{m \ell}\right)^{2}\right)-\sum_{\ell \in \Theta} \Lambda_{m \ell t}\left(\eta_{m \ell t}^{w}-\bar{\eta}_{m \ell}\right) \eta_{m \ell t}^{w}+\Lambda_{m p t}\left(\eta_{m p t}^{w}-\bar{\eta}_{m p}\right)}\right) \\
\times\left(C_{m t}^{r}\right)^{1-\rho} \quad(\mathrm{A}-24)
\end{gathered}
$$

Dividing equation (A-23) by equation (A-24) results in the equation for the share of types of assets in each worker's portfolio, which is identical for retirees, thus leading to condition (3-14):

$$
\left(1+\sum_{\ell \neq m} \frac{\Lambda_{m \ell t}}{2}\left(\eta_{m \ell t}-\bar{\eta}_{m \ell}\right)^{2}\right)\left(R_{p t}-R_{m t}\right)=\Lambda_{m p t}\left(\eta_{m p t}-\bar{\eta}_{m p}\right) R_{m t}
$$

for any $p \neq m$.

Once again, in order to find the Euler equation for consumption, we employ the same trick: multiply (A-23) by $\eta_{m m t}$ and (A-24) by $\sum_{\ell \neq m} \eta_{m \ell t}$ and sum them up. We then get:

$$
\omega_{m} C_{m t+1}^{w}+\left(1-\omega_{m}\right) \varepsilon_{m t+1}^{\frac{\sigma}{1-\sigma}} C_{m t+1}^{r}=\left(\frac{\beta \Omega_{m t+1} \sum_{\ell \in \Theta} \eta_{m \ell t} R_{\ell t}}{1+\sum_{\ell \neq m} \frac{\Lambda_{m \ell t}}{2}\left(\eta_{m \ell t}^{w}-\bar{\eta}_{m \ell}\right)^{2}}\right)^{\sigma} C_{m t}^{r}
$$

where $\omega_{m}$ is given by definition (3-17) in the text.

Once the Euler equation is found, it is necessary to guess the policy function for $C_{m t}^{w}$, which is given by equation (3-15) in the text:

$$
C_{m t}^{w}=\pi_{m t}\left(\sum_{\ell \in \Theta} R_{\ell t-1} A_{m \ell t-1}^{w}+H_{m t}^{w}+Z_{m t}^{w}\right)
$$

where $H_{m t}^{w}$ is the amount of human wealth of a worker at period $t$ and $Z_{m t}^{w}$ is the value of social security for the worker at $t$. The definitions for both variables are given below in Section A.3. For now, we substitute both guesses for policy 
functions, (3-9) and (3-15), for $C_{m t+1}^{r}$ and $C_{m t+1}^{w}$, respectively, in (A-25).

$$
\begin{aligned}
\omega_{m} \pi_{m t+1}\left(\sum_{\ell \in \Theta} R_{\ell t} A_{m \ell t}^{w}+H_{m t+1}^{w}\right. & \left.+Z_{m t+1}^{w}\right)+\left(1-\omega_{m}\right) \varepsilon_{m t+1}^{\frac{1}{1-\sigma}} \pi_{m t+1} \times \\
\times\left(\sum_{\ell \in \Theta} R_{\ell t} A_{m \ell t}^{r}+S_{m t+1}^{r}\right)= & \left(\frac{\beta \Omega_{m t+1} \sum_{\ell \in \Theta} \eta_{m \ell t} R_{\ell t}}{1+\sum_{\ell \neq m} \frac{\Lambda_{m \ell t}}{2}\left(\eta_{m \ell t}^{w}-\bar{\eta}_{m \ell}\right)^{2}}\right)^{\sigma} \pi_{m t} \times \\
& \times\left(\sum_{\ell \in \Theta} R_{\ell t-1} A_{m \ell t-1}^{w}+H_{m t}^{w}+Z_{m t}^{w}\right)
\end{aligned}
$$

To begin simplifying the equation above, first divide it by $\pi_{m t, t+1}$ and $\sum_{\ell \in \Theta} \eta_{m \ell t} R_{\ell t}$ to arrive at:

$$
\begin{gathered}
\omega_{m} \sum_{\ell \in \Theta} A_{m \ell t}^{w}+\left(1-\omega_{m}\right) \varepsilon_{m t+1}^{\frac{1}{1-\sigma}} \sum_{\ell \in \Theta} A_{m \ell t}^{r}+\omega_{m} \frac{H_{m t+1}^{w}+Z_{m t+1}^{w}}{\sum_{\ell \in \Theta} \eta_{m \ell t} R_{\ell t}}+\left(1-\omega_{m}\right) \times \\
\times \varepsilon_{m t+1}^{\frac{1}{1-\sigma}} \frac{S_{m t+1}^{r}}{\sum_{\ell \in \Theta} \eta_{m \ell t} R_{\ell t}}=\left(\frac{\beta \Omega_{m t+1}}{1+\sum_{\ell \neq m} \frac{\Lambda_{m \ell t}}{2}\left(\eta_{m \ell t}^{w}-\bar{\eta}_{m \ell}\right)^{2}}\right)^{\sigma}\left(\sum_{\ell \in \Theta} \eta_{m \ell t} R_{\ell t}\right)^{\sigma-1} \times \\
\times \frac{\pi_{m t}}{\pi_{m t+1}}\left(\sum_{\ell \in \Theta} R_{\ell t-1} A_{m \ell t-1}^{w}+H_{m t}^{w}+Z_{m t}^{w}\right)
\end{gathered}
$$

Note that $\sum_{\ell \in \Theta} A_{m \ell t}^{w}$ and $\sum_{\ell \in \Theta} A_{m \ell t}^{r}$ are identical, since in this case we are dealing with a just-retired retiree whose revenue sources for the current period come from his or her labor income from the previous one. Therefore, it is possible to factorize (A-27) and after this substitute the common factor, $\sum_{\ell \in \Theta} A_{m \ell t}^{w}$, for the worker's budget constraint. After the factorization and the substitution, we divide the entire equation by the common factor, which will turn out to be $\omega_{m}$ and also multiply it by portfolio cost factor, eventually arriving at : 


$$
\begin{aligned}
& \sum_{\ell \in \Theta} R_{\ell t-1} A_{m \ell t-1}^{w}+W_{m t}^{w}+T_{m t}^{w}-C_{m t}^{w}+ \\
& +\omega_{m} \frac{H_{m t+1}^{w}+Z_{m t+1}^{w}}{\frac{\Omega_{m t+1} \sum_{\ell \in \Theta} \eta_{m \ell t} R_{\ell t}}{1+\sum_{m \neq n} \frac{\Lambda_{n m t}}{2}\left(\eta_{n m t}-\bar{\eta}_{n m}\right)^{2}}}+\left(1-\omega_{m}\right) \varepsilon_{m t+1}^{\frac{1}{1-\sigma}} \frac{S_{m t+1}^{r}}{\frac{\Omega_{m t+1} \sum_{\ell \in \Theta} \eta_{m \ell t} R_{\ell t}}{1+\sum_{m \neq n} \frac{\Lambda_{n m t}}{2}\left(\eta_{n m t}-\bar{\eta}_{n m}\right)^{2}}}=\beta^{\sigma} \times \\
& \times\left(\frac{\Omega_{m t+1} \sum_{\ell \in \Theta} \eta_{m \ell t} R_{\ell t}}{1+\sum_{m \neq n} \frac{\Lambda_{n m t}}{2}\left(\eta_{n m t}-\bar{\eta}_{n m}\right)^{2}}\right)^{\sigma-1} \frac{\pi_{m t}}{\pi_{m t+1}}\left(\sum_{\ell \in \Theta} R_{\ell t-1} A_{m \ell t-1}^{w}+H_{m t}^{w}+Z_{m t}^{w}\right)
\end{aligned}
$$

Substitute (3-15) for $C_{m t}^{w}$ and It is finally time now to use the recursive definitions of $H_{m t+1}^{w}$ and $Z_{m t+1}^{w}$ in order to further simplify the equation above. By applying the definitions, we get:

$$
\begin{aligned}
& \left(1-\pi_{m t}\right)\left(\sum_{\ell \in \Theta} R_{\ell t-1} A_{m \ell t-1}^{w}+H_{m t}^{w}+Z_{m t}^{w}\right)=\beta^{\sigma} \times \\
\times & \left(\frac{\Omega_{m t+1} \sum_{\ell \in \Theta} \eta_{m \ell t} R_{\ell t}}{1+\sum_{m \neq n} \frac{\Lambda_{n m t}}{2}\left(\eta_{n m t}-\bar{\eta}_{n m}\right)^{2}}\right)^{\sigma-1} \frac{\pi_{m t}}{\pi_{m t+1}}\left(\sum_{\ell \in \Theta} R_{\ell t-1} A_{m \ell t-1}^{w}+H_{m t}^{w}+Z_{m t}^{w}\right)
\end{aligned}
$$

By crossing out the common terms from both sides of the equation and rearranging, we finally get the difference equation for the worker's mpcw, $(3-16)$ :

$$
\pi_{m t}=1-\beta^{\sigma}\left(\frac{\Omega_{m t+1} \sum_{\ell \in \Theta} \eta_{m \ell t}^{w} R_{\ell t}}{1+\sum_{\ell \neq m} \frac{\Lambda_{m \ell t}}{2}\left(\eta_{m \ell t}^{w}-\bar{\eta}_{m \ell}\right)^{2}}\right)^{\sigma-1} \frac{\pi_{m t}}{\pi_{m t+1}}
$$

What remains now is to verify whether the guess for the value function obtains now that the problem is solved. After substituting the guess for its format into equation (3-12) and rearranging the resulting equation a little, we get the following:

$$
\Delta_{m t}^{w} C_{m t}^{w}=\left[\left(C_{m t}^{w}\right)^{\rho}+\beta\left(\omega_{m} C_{m t+1}^{w}+\left(1-\omega_{m}\right) \frac{\Delta_{m t+1}^{r}}{\Delta_{m t+1}^{w}} C_{m t+1}^{r}\right)^{\rho}\left(\Delta_{m t+1}^{w}\right)^{\rho}\right]^{\frac{1}{\rho}}
$$

We can substitute then the Euler equation (A-25) into (A-30) and get: 
$\Delta_{m t}^{w} C_{m t}^{w}=\left[\left(C_{m t}^{w}\right)^{\rho}+\beta\left(\left(\frac{\beta \Omega_{m t+1} \sum_{\ell \in \Theta} \eta_{m \ell t} R_{\ell t}}{1+\sum_{\ell \neq m} \frac{\Lambda_{m \ell t}}{2}\left(\eta_{m \ell t}^{w}-\bar{\eta}_{m \ell}\right)^{2}}\right)^{\sigma} C_{m t}^{w}\right)^{\rho}\left(\Delta_{m t+1}^{w}\right)^{\rho}\right]^{\frac{1}{\rho}}$

Canceling $C_{m t}^{w}$ from the equation and then rearranging it will lead to the equation below:

$$
\frac{1}{\left(\Delta_{m t}^{w}\right)^{\rho}}=1-\beta^{\sigma}\left(\frac{\Omega_{m t+1} \sum_{\ell \in \Theta} \eta_{m \ell t} R_{\ell t}}{1+\sum_{\ell \neq m} \frac{\Lambda_{m \ell t}}{2}\left(\eta_{m \ell t}^{w}-\bar{\eta}_{m \ell}\right)^{2}}\right)^{\sigma-1} \frac{\left(\Delta_{m t+1}^{w}\right)^{\rho}}{\left(\Delta_{m t}^{w}\right)^{\rho}}
$$

Comparing equation (A-32) to equation (3-16) will show that the guess for the policy function is correct: $\Delta_{m t}^{w}=\pi_{m t}^{-1 / \rho}$. This finishes the derivation of the worker's problem, next section aggregates the behavior of agents.

\section{A. 2}

\section{Aggregation}

In order to begin aggregating variables, it is important to note that since all workers provide the same amount of work to production, their wages will be identical. Taxes, an endogenous variable, will also be assumed to be paid equally by workers, since they will only differ with respect to their ages. Pension payments, an exogenous variable, will also be assumed to be paid equally to retirees for the same reason. Hence, we have the following expressions:

$$
W_{m t}=N_{m t}^{w} W_{m t}^{w j} \quad T_{m t}=N_{m t}^{w} T_{m t}^{w j} \quad E_{m t}=N_{m t}^{r} E_{m t}^{r j k}
$$

for any $r, j$, since age does not influence these variables.

\section{A.2.1}

\section{Consumption}

Summing consumption across retirees and workers from country $m$ it is possible to find the total consumption functions for both groups. Defining the sum operator $\sum_{z}$ as the sum of values across all individuals within group $z$, the total consumption of retirees, $C_{m t}^{r}$, is given by:

$$
C_{m t}^{r}=\sum_{r} C_{m t}^{r j k}=\varepsilon_{m t} \pi_{m t}\left(\sum_{\ell \in \Theta}\left(R_{\ell t-1} \sum_{r} A_{m \ell t-1}^{r j k}\right)+\sum_{r} S_{m t}^{r j k}\right)
$$


The total value of assets of some country $\ell$ held by retirees will be given simply by $A_{m \ell t}^{r}$ and the value of social security for them by $S_{m t}$. The recursive formula for the aggregate value of social security can be found in Section A.3. Substituting these definitions into the expression above yields equation (3-19):

$$
C_{m t}^{r}=\varepsilon_{m t} \pi_{m t}\left(\sum_{\ell \in \Theta} R_{\ell t-1} A_{m \ell t-1}^{r}+S_{m t}\right)
$$

The same can be done in order to find worker's total consumption, which is given by equation (3-20):

$$
C_{m t}^{w}=\pi_{m t}\left(\sum_{\ell \in \Theta} R_{\ell t-1} A_{m \ell t-1}^{w}+H_{m t}+Z_{m t}\right)
$$

where $A_{m \ell t}^{w} \equiv \sum_{w} A_{m \ell t}^{w j}$ is the value of country $\ell$ 's assets held by all workers in country $m, H_{m t} \equiv \sum_{w} H_{m t}^{w j}$ is the value of human wealth summed across all workers and $Z_{m t} \equiv \sum_{w} Z_{m t}^{w j}$ is the total value of social security for workers at $t$. The following section contains the recursive formulas for aggregate human wealth and social security value for workers.

Total consumption will thus be given by the sum of total consumption for retirees and workers, which leads to equation (3-22).

\section{A.2.2}

Assets

Given the life-cycle nature of this economy, it will present an extra state variable in contrast to the conventional model of infinitely-lived agents. This variable is the share of total assets that are held by retirees and captures the heterogeneity in nonhuman asset holdings between retirees and workers. The amount of assets held by retirees evolve according to the following law of motion:

$$
\begin{gathered}
\sum_{\ell \in \Theta} A_{m \ell t}^{r}=\frac{1}{1+\sum_{\ell \neq m} \frac{\Lambda_{m \ell t}}{2}\left(\eta_{m \ell t}-\bar{\eta}_{m \ell}\right)^{2}}\left(\sum_{\ell \in \Theta} R_{\ell t-1} A_{m \ell t-1}^{r}+E_{m t}-C_{m t}^{r}\right)+ \\
+\left(1-\omega_{m}\right) \frac{1}{1+\sum_{\ell \neq m} \frac{\Lambda_{m \ell t}}{2}\left(\eta_{m \ell t}-\bar{\eta}_{m \ell}\right)^{2}}\left(\sum_{\ell \in \Theta} R_{\ell t-1} A_{m \ell t-1}^{w}+W_{m t}-T_{m t}-C_{m t}^{w}\right)
\end{gathered}
$$

First, from workers' aggregate budget constraint, substitute the total amount of workers' assets into the second term of the right-hand side of the equation. Now we substitute retirees' consumption functions for $C_{m t}^{r}$, 
respectively and rewrite retirees and workers' total value of nonhuman assets as shares of total assets.

$$
\begin{gathered}
\lambda_{m t} \sum_{\ell \in \Theta} A_{m \ell t}=\frac{1}{1+\sum_{\ell \neq m} \frac{\Lambda_{m \ell t}}{2}\left(\eta_{m \ell t}-\bar{\eta}_{m \ell}\right)^{2}}\left(\lambda_{m t-1} \sum_{\ell \in \Theta} R_{\ell t-1} A_{m \ell t-1}+E_{m t}-\right. \\
\left.-\varepsilon_{m t} \pi_{m t}\left(\lambda_{m t-1} \sum_{\ell \in \Theta} R_{\ell t-1} A_{m \ell t-1}+S_{m t}\right)\right)+\left(1-\omega_{m}\right) \frac{\left(1-\lambda_{m t}\right) \sum_{\ell \in \Theta} A_{m \ell t}}{\omega_{m}}
\end{gathered}
$$

After many rearrangements, it is possible to find the final formula for the law of motion of the retirees' share of nonhuman assets, (3-23):

$$
\lambda_{m t}=\left(1-\omega_{m}\right)+\frac{\omega_{m}}{1+\sum_{\ell \neq m} \frac{\Lambda_{m \ell t}}{2}\left(\eta_{m \ell t}-\bar{\eta}_{m \ell}\right)^{2}}\left(\left(1-\varepsilon_{m t} \pi_{m t}\right) \lambda_{m t-1}\right.
$$

$$
\left.\frac{\sum_{\ell \in \Theta} R_{\ell t-1} A_{m \ell t-1}}{A_{m t}}+\frac{E_{m t}-\varepsilon_{m t} \pi_{m t} S_{m t}}{A_{m t}}\right)
$$

where $A_{m t} \equiv \sum_{\ell \in \Theta} A_{m \ell t}$

\section{A.3}

\section{Human Wealth and Social Security Value}

\section{A.3.1}

Human Wealth

Human wealth is defined as the sum of discounted flows of labor earnings minus taxes. The discount rate, however, will have to be adjusted by the costs of portfolio and probabilities of workers turning into retirement:

$$
\begin{aligned}
& H_{m t}^{w} \equiv \sum_{v=0}^{\infty} \frac{W_{m, t+v}^{w}-T_{m, t+v}^{w}}{\prod_{i=1}^{v} \frac{\Omega_{m t+i} \sum_{\ell \in \Theta} \eta_{m \ell, t+i-1} R_{\ell, t+i-1}}{\omega_{m, t+i-1, t+i}\left(1+\sum_{\ell \neq m} \frac{\Lambda_{m \ell t}}{2}\left(\eta_{m \ell, t+i-1}-\bar{\eta}_{m \ell}\right)^{2}\right)}}= \\
& =W_{t}^{w}-T_{t}^{w}+\frac{\omega_{m} H_{m t+1}^{w}}{\frac{\Omega_{m t+1} \sum_{\ell \in \Theta} \eta_{m \ell t} R_{\ell t}}{1+\sum_{\ell \neq m} \frac{\Lambda_{m \ell t}}{2}\left(\eta_{m \ell t}-\bar{\eta}_{m \ell}\right)^{2}}}
\end{aligned}
$$


When aggregated across workers the value of human wealth is simply the individual value times the number of workers at the moment. This follows from the fact that wages and taxes at one determinate moment are equal across workers and that all workers discount the future at the same rate. This will result in just a simple adjustment in the individual formula in order to account for the labor force growth rate. The recursive formula is then given by:

$$
H_{m t}=W_{t}-T_{t}+\frac{\omega_{m} H_{m t+1}}{\frac{\left(1+n_{m t, t+1}\right) \Omega_{m t+1} \sum_{\ell \in \Theta} \eta_{m \ell t} R_{\ell t}}{1+\sum_{\ell \neq m} \frac{\Lambda_{m \ell t}}{2}\left(\eta_{m \ell t}-\bar{\eta}_{m \ell}\right)^{2}}}
$$

\section{A.3.2}

\section{Social Security Value}

The value of future pension payments to workers is given by the sum of the present values of each possible future scenario of retirement weighted by its corresponding probability. The discount rate is once again given by a weighted average of interest rates of all countries adjusted by the cost of portfolio:

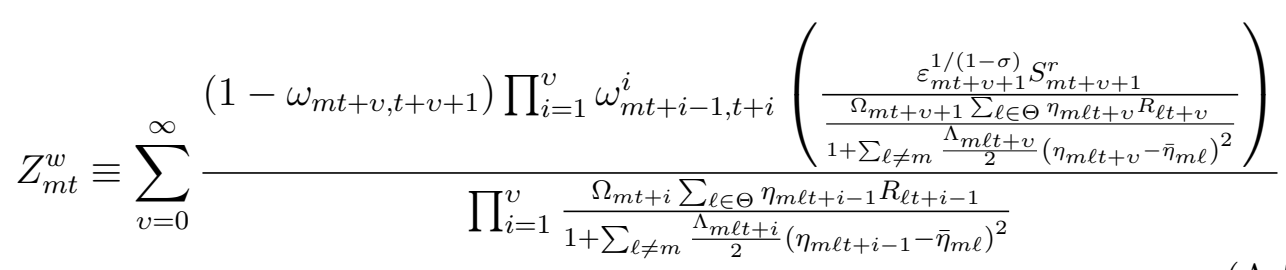

Note that the value of social security for a retiree at any time $t+v+1$ must be multiplied by $\varepsilon_{m t+v+1}^{1 /(1-\sigma)}$ in order to account for the difference in mpcw's between workers and retirees. Equation (A-7) can be rewritten recursively as:

$$
Z_{m t}^{w}=\left(1-\omega_{m}\right) \frac{\varepsilon_{m t+1}^{\frac{1}{1-\sigma}} S_{m t+1}^{r}}{\frac{\Omega_{m t+1} \sum_{\ell \in \Theta} \eta_{m \ell t} R_{\ell t}}{1+\sum_{\ell \neq m} \frac{\Lambda_{m \ell t}}{2}\left(\eta_{m \ell t}-\bar{\eta}_{m \ell}\right)^{2}}}+\omega_{m} \frac{Z_{m t+1}^{w}}{\frac{\Omega_{m t+1} \sum_{\ell \in \Theta} \eta_{m \ell t} R_{\ell t}}{1+\sum_{\ell \neq m} \frac{\Lambda_{m \ell t}}{2}\left(\eta_{m \ell t}-\bar{\eta}_{m \ell}\right)^{2}}}
$$

The aggregate value of social security for retirees is simply the value for a single retiree times the current number of retirees, just like the case of human wealth for workers, and follows from the fact that every retiree receives the same pension payment as the others and discount future cash flows also equally. The recursive expression for $S_{m t}$, the aggregate value of social security for retirees, can then be given by:

$$
S_{m t}=E_{m t}+\frac{S_{m t+1}}{\frac{\psi_{m t+1}\left(1+n_{m t, t+1}\right)}{\psi_{m t} \gamma_{m t, t+1}} \frac{\sum_{\ell \in \Theta} \eta_{m \ell t}^{r} R_{\ell t}}{1+\sum_{\ell \neq m} \frac{\Lambda_{m \ell t}}{2}\left(\eta_{m \ell t}^{r}-\bar{\eta}_{m \ell}\right)^{2}}}
$$

where the term $\left(1+n_{m t, t+1}\right) \psi_{m t+1} / \psi_{m t}$ adjusts the expression for the growth 
in the number of retirees. Given that retirees value social security equally, its value for workers will also be the same across them all. The recursive formula for $Z_{m t}$ will thus be:

$$
Z_{m t}=\left(1-\omega_{m}\right) \frac{\varepsilon_{m t+1}^{\frac{1}{1-\sigma}} S_{m t+1}}{\frac{\psi_{m t+1}\left(1+n_{m t, t+1}\right) \Omega_{m t+1} \sum_{\ell \in \Theta} \eta_{m \ell t} R_{\ell t}}{1+\sum_{\ell \neq m} \frac{\Lambda_{m \ell t}}{2}\left(\eta_{m \ell t}-\bar{\eta}_{m \ell}\right)^{2}}}+\omega_{m} \frac{Z_{m t+1}}{\frac{\left(1+n_{m t, t+1}\right) \Omega_{m t+1} \sum_{\ell \in \Theta} \eta_{m \ell t} R_{\ell t}}{1+\sum_{\ell \neq m} \frac{\Lambda_{m \ell t}}{2}\left(\eta_{m \ell t}-\bar{\eta}_{m \ell}\right)^{2}}}
$$

\section{A.4}

\section{Firm's problem}

Since the representative firm faces adjustment costs with respect to changes in investment, its problem becomes dynamic. It will then choose $N_{m t}^{w}$, $I_{m t}$ and $K_{m t}$ to solve:

$$
\begin{aligned}
& V\left(I_{m t-1}, K_{m t-1}\right)=\max _{N_{m t}^{w}, I_{m t}, K_{m t}}\left[\left(X_{m t} N_{m t}^{w}\right)^{\alpha} K_{m t-1}^{1-\alpha}-\right. \\
& \left.-W_{m t}^{w} N_{m t}^{w}-I_{m t}+\frac{V\left(I_{m t}, K_{m t}\right)}{R_{m t}}\right]
\end{aligned}
$$

subject to (3-26):

$$
K_{m t}=(1-\delta) K_{m t-1}+\left(1-\frac{\phi}{2}\left(\frac{I_{m t}}{I_{m t-1}}-\left(1+n_{m t-1, t}+x_{m t-1, t}\right)\right)^{2}\right) I_{m t}
$$

The first-order condition with respect to the number of workers is identical to the conventional problem with no adjustment costs and renders that the real wage must be equal to the marginal product of the marginal worker:

$$
W_{m t}^{w}=\alpha \frac{Y_{m t}}{N_{m t}^{w}}
$$

Call the Lagrange multiplier on the constraint (3-26) $q_{m t}$, then the firstorder condition with respect to investment and capital are respectively: 


$$
\begin{array}{r}
q_{m t}\left[1-\frac{\phi}{2}\left(\frac{I_{m t}}{I_{m t-1}}-\left(1+n_{m t-1, t}+x_{m t-1, t}\right)\right)^{2}-\phi\left(\frac{I_{m t}}{I_{m t-1}}-\left(1+n_{m t-1, t}+\right.\right.\right. \\
\left.\left.\left.+x_{m t-1, t}\right)\right)\right]=1-\frac{1}{R_{m t}} \frac{\partial V\left(I_{m t}, K_{m t}\right)}{\partial I_{m t}}
\end{array}
$$

and

$$
\frac{1}{R_{m t}} \frac{\partial V\left(I_{m t}, K_{m t}\right)}{\partial K_{m t}}=q_{m t}
$$

The Envelope Theorem provides the formulas for the partial derivatives:

$$
\frac{\partial V\left(I_{m t-1}, K_{m t-1}\right)}{\partial I_{m t-1}}=\phi\left(\frac{I_{m t}}{I_{m t-1}}-\left(1+x_{m t-1, t}+n_{m t-1, t}\right)\right)\left(\frac{I_{m t}}{I_{m t-1}}\right)^{2} q_{m t}
$$

and

$$
\frac{\partial V\left(I_{m t-1}, K_{m t-1}\right)}{\partial K_{m t-1}}=(1-\alpha) \frac{Y_{m t}}{K_{m t-1}}+(1-\delta) q_{m t}
$$

Substituting (A-15) and (A-16) into equations (A-13) and (A-14), respectively, yields:

$$
\begin{aligned}
& q_{m t}\left[1-\frac{\phi}{2}\left(\frac{I_{m t}}{I_{m t-1}}-\left(1+n_{m t-1, t}+x_{m t-1, t}\right)\right)^{2}-\phi\left(\frac{I_{m t}}{I_{m t-1}}-\left(1+n_{m t-1, t}+\right.\right.\right. \\
& \left.\left.\left.\quad+x_{m t-1, t}\right)\right)\right]=1-\frac{\phi q_{m t+1}}{R_{m t}}\left(\frac{I_{m t+1}}{I_{m t}}-\left(1+n_{m t, t+1}+x_{m t, t+1}\right)\right)\left(\frac{I_{m t+1}}{I_{m t}}\right)^{2}
\end{aligned}
$$

and

$$
q_{m t}=\frac{1}{R_{m t}}\left[(1-\alpha) \frac{Y_{m t+1}}{K_{m t}}+(1-\delta) q_{m t+1}\right]
$$

Now note that, from the first equation above, if $\phi=0$, then $q_{m t}=1$, which implies in the second equation that the real interest rate in country $m$ will equalize the marginal productivity of capital net of depreciation:

$$
R_{m t}=(1-\alpha) \frac{Y_{m t+1}}{K_{m t}}+(1-\delta)
$$


B

\section{Statistical Appendix}

Data for calibration of exogenous processes and analysis of simulation output were obtained from a great variety of sources. Table (B.1) below provides the sources for each series used: 
TABle B.1: Data sources

\begin{tabular}{|c|c|c|}
\hline $\begin{array}{l}\text { Variable } \\
\text { (Time Range) }\end{array}$ & $\begin{array}{l}\text { Country } \\
\text { Source }\end{array}$ & \\
\hline Technological Growth & $\begin{array}{c}\text { All } \\
(1990-2012)\end{array}$ & $\begin{array}{l}\text { Groningen Growth and } \\
\text { Development Center: } \\
\text { Total Economy Database }\end{array}$ \\
\hline $\begin{array}{l}\text { Growth of } \\
\text { Working-Age Pop. }\end{array}$ & & \\
\hline Life Expectancy & $\begin{array}{c}\text { All } \\
(1990-2100) \\
\text { Forecasts } \\
\text { after } 2010\end{array}$ & $\begin{array}{l}\text { United Nations } \\
\text { World Population Prospects: } \\
\text { the } 2012 \text { Revision }\end{array}$ \\
\hline Old-Age Supp. Ratio & & \\
\hline Net Debt Outstanding & All & $\begin{array}{c}\text { International Monetary } \\
\text { Fund: World Economic } \\
\text { Outlook (WEO) and } \\
\text { International } \\
\text { Financial Statistics (IFS) }\end{array}$ \\
\hline Gov't consumption & All & $\begin{array}{c}\text { World Bank: World } \\
\text { Development Indicators (WDI) }\end{array}$ \\
\hline \multirow[t]{3}{*}{ Pension expenditures } & $\begin{array}{l}\text { United States } \\
(1973-2050) \\
\text { Forecasts } \\
\text { after } 2012\end{array}$ & $\begin{array}{l}\text { OECD: Pensions at a Glance } \\
\text { Congressional Budget Office }\end{array}$ \\
\hline & $\begin{array}{c}\text { G6 } \\
(1980-2050) \\
\text { Forecasts } \\
\text { after } 2010\end{array}$ & $\begin{array}{l}\text { OECD: Pensions at a Glance } \\
\text { Forecasts for Japan: } \\
\text { Ministry of Health } \\
\text { Labor and Welfare }\end{array}$ \\
\hline & China (2012) & $\begin{array}{l}\text { OECD: Pensions at a } \\
\text { Glance Asia/Pacific } \\
2013\end{array}$ \\
\hline GDP & $\begin{array}{c}\text { All } \\
(1970-2012)\end{array}$ & WDI \\
\hline
\end{tabular}




\begin{tabular}{|c|c|c|}
\hline $\begin{array}{l}\text { Net Domestic } \\
\text { Investment }\end{array}$ & $\begin{array}{l}\text { United States } \\
(1970-2012) \\
\text { G6 and China } \\
(1970-2012)\end{array}$ & $\begin{array}{c}\text { Federal Reserve Bank } \\
\text { of St. Louis } \\
\text { WDI }\end{array}$ \\
\hline $\begin{array}{l}\text { Net National } \\
\text { Savings }\end{array}$ & $\begin{array}{c}\text { United States } \\
(1970-2012) \\
\text { G6 } \\
(1977-2012) \\
\text { China } \\
(1982-2012)\end{array}$ & WDI \\
\hline Balance of Trade & $\begin{array}{c}\text { United States } \\
(1970-2012) \\
\text { G6 } \\
(1977-2012) \\
\text { China } \\
(1982-2012) \\
\end{array}$ & $\begin{array}{c}\text { Bureau of Economic } \\
\text { Analysis and WDI } \\
\text { WDI }\end{array}$ \\
\hline Current Account & $\begin{array}{l}\text { United States } \\
(1970-2012) \\
\text { G6 and China } \\
(1980-2012)\end{array}$ & $\begin{array}{c}\text { Bureau of Economic } \\
\text { Analysis and WEO } \\
\text { WEO }\end{array}$ \\
\hline Real Interest Rates & $\begin{array}{c}\text { All } \\
(1980-2012)\end{array}$ & WDI \\
\hline
\end{tabular}




\section{C}

\section{Alternative Series for TFP}

In this section I redo the quantitative exercise with TFP series which are consistent with the provided series for China, but are, on the other hand, inconsistent with the model in itself, since were obtained from an external source. The method was the same employed for China: since the TFP growth rates from the GGDC are only available from 1990 through 2012, for the years before they are estimated using the series of the growth rate of average productivity. The correlation between both series for the United States and the G6 are 0.86 and 0.97 , respectively.

The results are plotted below. We see that the simulated series for China still appears to track the data relatively well, but the correlation drops considerably. There is an improvement in the simulation for the G6, but only as far as the trends of the group's imbalances are concerned. For the United States, however, the fit turns out to be far worse than in the other case.

Figure C.1: Simulations with alternative TFP growth (\% GDP)

(C.1(A)) U.S. Curr. Acc.

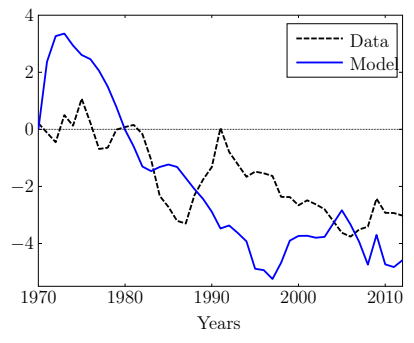

(C.1(B)) G6 Curr. Acc.

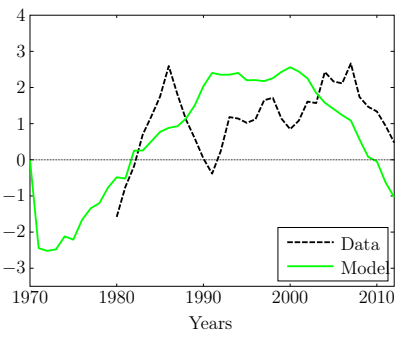

(C.1(c)) CN Curr. Acc.

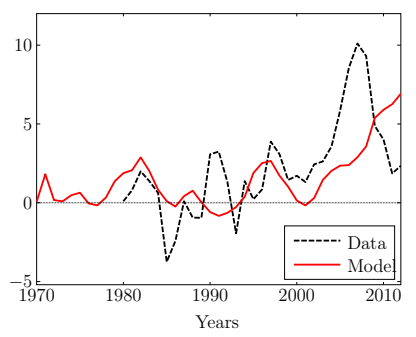

TABle C.1

\begin{tabular}{lccc}
\hline \hline Correlation & US & G6 & China \\
\hline \hline Current Account & $0.7005(0.8279)$ & $0.2273(0.0048)$ & $0.4283(0.7091)$ \\
\hline
\end{tabular}

